ENVIRONMENTAL AND ETHNO-CULTURAL GROUPS WORKING TOGETHER: AN EXAMINATION OF TORONTO-BASED ENVIRONMENTAL PROGRAMS

By

Karima Esmail, B.U.R.Pl. (Hon.) Toronto, Ontario, Canada, 2002

A thesis presented to Ryerson University

in partial fulfilment of the

requirements for the degree of

Master of Applied Science

in the Program of

Environmental Applied Science and Management

Toronto, Ontario, Canada, 2005

CC Karima Esmail, 2005 
UMI Number: EC53032

\section{All rights reserved \\ INFORMATION TO USERS}

The quality of this reproduction is dependent upon the quality of the copy submitted. Broken or indistinct print, colored or poor quality illustrations and photographs, print bleed-through, substandard margins, and improper alignment can adversely affect reproduction.

In the unlikely event that the author did not send a complete manuscript and there are missing pages, these will be noted. Also, if unauthorized copyright material had to be removed, a note will indicate the deletion.

UMI Microform EC53032

Copyright 2008 by ProQuest LLC

All rights reserved. This microform edition is protected against unauthorized copying under Title 17, United States Code.

ProQuest LLC

789 East Eisenhower Parkway

P.O. Box 1346

Ann Arbor, MI 48106-1346 



\section{Author's Declaration}

I hereby declare that I am the sole author of this thesis.

I authorize Ryerson University to lend this thesis to other institutions or individuals for the purpose of scholarly research.

\section{Signature}

I further authorize Ryerson University to reproduce this thesis by photocopying or by other means, in total or in part, at the request of other institutions or individuals for the purpose of scholarly research.

Signature 


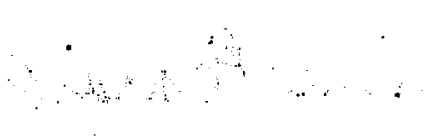

$\therefore \quad 3$ 


\begin{abstract}
Environmental and Ethno-Cultural Groups Working Together: An Examination of TorontoBased Environmental Programs
\end{abstract}

Karima Esmail, Master of Applied Science (2005) in the program of Environmental Applied Science and Management Ryerson University, Toronto

This research explores how environmental groups in Toronto are encouraging ethno-cultural groups to participate in environmental activities. This research intersects three areas: the environmental movement, volunteering and ethno-cultural diversity. A literature review of these areas was undertaken. Semi-structured interviews with key informants from environmental groups in Toronto were conducted. Key informants were individuals involved in the planning and implementation of selected environmental programs.

The findings of this research suggest:

- The terms volunteer and participant can have different meanings

- Ethno-culturally specific data is not collected by environmental groups

- Environmental groups do no ask volunteers and participants about motivations

- Local interactions are important

- Environmental programs are multi-faceted

- Environmental groups do not work in isolation

- Funding affects long-term program planning

- Ethno-cultural sensitivity is important

Based on these findings, best practices of how environmental groups can encourage ethnocultural groups to participate in environmental activities are proposed. 


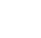




\section{Acknowledgements}

I would like to thank all of the people who have helped me to complete this thesis.

I especially would like to thank my advisor, Dr. Beth Moore Milroy, whose expertise and guidance has shaped this thesis and shown me that academic research can be a stimulating experience. This study has greatly benefited from her insight on environmental and multicultural issues.

I would also like to thank all of the key informants who participated in this study for their time and openness in speaking about their environmental programs. Without them, this study, its findings and directions for future research would not have been realised.

I extend my gratitude to my best friend for his words of encouragement.

Finally, I would like to thank my parents. They are truly the wind beneath my wings. 


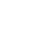




\section{Table of Contents}

Page No.

\section{Chapter I: Background}

$\begin{array}{lr}\text { About the Study } & 1\end{array}$

Main Concepts $\quad 2$

The Environmental Movement $\quad \cdot 3$

Defining Environmental Movement 3

Environmental Racism and Environmental Justice 3

Civic Environmentalism $\quad 4$

Citizen Participation and Environmental Education $\quad 5$

Volunteer Environmental Stewardship $\quad 5$

$\begin{array}{ll}\text { Ethno-cultural Diversity } & 6\end{array}$

Defining Ethno-culture $\quad 7$

$\begin{array}{ll}\text { Multiculturalism } & 8\end{array}$

Assimilation, Integration and Citizenship 9

Visible Minorities, People of Colour, Immigrants and New Canadians $\quad 10$

2001 Census - Immigration Trends 11

$\begin{array}{ll}\text { Volunteering } & 13\end{array}$

Defining Volunteering and Active Citizenship 13

Civic Participation $\quad 14$

Multiculturalism and Social Capital $\quad 14$

$\begin{array}{lr}\text { Discussion and Summary of Key Points } & 15\end{array}$

\section{Chapter II: Enlargement}

The Environmental Movement and Volunteering 19

Volunteer Motivations in the Environmental Activities $\quad \mathbf{2 0}$

Barriers to Volunteering in Environmental Activities $\quad 21$

Volunteering and Ethno-cultural Diversity 23

The National Survey of Giving, Volunteering and Participating 2

A Profile of Ontario's Volunteers

Immigrants and Volunteering $\quad \mathbf{2 7}$

Ethnic Diversity Survey $\quad \mathbf{2 8}$ 
Ethno-cultural Diversity and the Environmental Movement

Environmental Concern and Culture $\quad 32$

Ethno-cultural Groups and the Environmental Movement

The Environmental Movement and the Participation of Ethno-cultural Groups in Canada

Immigrants in the Environmental Movement

Discussion and Summary of Key Points

\section{Chapter III: Methods}

Purpose and Rationale

Primary Data Collection Methods

Informed Consent Process

Organisation of Interview Protocol

Setting Up the Interview

Secondary Data Collection Methods

Sampling Method

Sample Selection

Key Informants

Data Analysis

Discussion and Summary of Key Points

\section{Chapter IV: Findings}

Synopsis of Environmental Programs

Volunteer and Participant Can Have Different Meanings $\quad 65$

Information Gaps Exist: Ethno-cultural Data Not Collected 67

Information Gaps Exist: Motivations Not Formally Collected 
Local Level Interactions are Important

Recruitment

Finding an Ambassador or Representative

Local Media: Radio, Television and Newspapers

Locally Accessible Venues

77

Accessing ESL Classes

Environmental Programs are Multi-faceted

Environmental Groups Do Not Work in Isolation

Funding Affects Long-term Program Planning

Ethno-Cultural Sensitivity is Important

Discussion and Summary of Key Points

Chapter V: Analysis

Expanding the Definition of Volunteer Environmental Stewardship

Exploring the Relationship between Funding and Environmental Programming

Deliberate Targeting and Deliberate Siting

Active and Passive Forms of Interaction

Environmental Discourse: Integration and Assimilation

Addressing the Data Gaps

Including or Segmenting

Traces that Networks Exist

Discussion and Summary of Key Points

\section{Chapter VI: Conclusions}

Summary of Study

List of Techniques 


\section{List of Figures}

Figure 1: Scope of Background Research

Figure 2: Visible Minorities in Canada

Figure 3: Scope of Literature Review

Figure 4: Barriers and Responses to Volunteering

Figure 5: Where Canadians Volunteer

Figure 6: Motivations for Volunteering

Figure 7: Barriers to Volunteering

Figure 8: Volunteer Recruitment Methods

Figure 9: Volunteer Activities - Ontario

Figure 10: Reasons for Volunteering - Ontario

Figure 11: Sense of Belonging by Ethnic Group

Figure 12: Importance of Customs and Traditions by Ethnic Group

Figure 13: Sources of Environmental Groups Initially Selected

Figure 14: Participating Environmental Groups

Figure 15: Summary of Participating Environmental Groups

Figure 16: Summary of Environmental Programs Examined

Figure 17: Distinguishing Between Volunteers and Participants 


\section{Appendix}

$\begin{array}{ll}\text { Appendix A: Basic and Adjunct Stewardship Types } & 109\end{array}$

$\begin{array}{ll}\text { Appendix B: Interview Protocol } & 111\end{array}$

$\begin{array}{ll}\text { Appendix C: Isolating the Selected Environmental Programs } & 113\end{array}$

$\begin{array}{lr}\text { Works Cited } & 115\end{array}$ 


\author{
.
}




\section{Chapter I: Background}

\section{About the Study}

This study is about how ethno-cultural diversity has influenced the environmental movement in Toronto. Specifically, this study examines how environmental organisations are encouraging ethno-cultural groups to participate in environmental activities in Toronto. In answering this question, the following questions will also be answered:

- What types of interactions occur between environmental and ethno-cultural groups?

- How are these interactions planned and implemented?

- What are the characteristics of the environmental groups involved?

- What are the characteristics of the ethno-cultural groups involved?

- What are the best practices of environmental groups working with ethno-cultural groups?

This study has been developed out of the perceived non-representativeness of environmental groups when ethno-cultural dimensions are considered within the environmental movement. Often the environmental movement is viewed as a white and middle-class movement that does not facilitate the participation of other ethno-cultural groups. Toronto's population is increasingly becoming ethno-culturally diverse and the growth in population of non-white ethnocultural groups is outpacing white ethno-cultural groups which have traditionally settled in Canada. Because of this, environmental groups need be responsive to this demographic change in order to keep pace with the diverse population that will ultimately volunteer in its programs and participate in the larger environmental movement. Toronto's environmental groups can acknowledge this ethno-culturally diverse population by encouraging these groups to participate in environmental activities.

Chapter 1 presents a review of literature that speaks to the basic concepts around which this study was framed and Chapter 2 presents a more detailed review of literature that is specific to the research question. The current body of literature surrounding the research question is 
fragmented and does not provide a full answer. This study was developed out of this circumstance, in an attempt to provide a comprehensive and current account of how environmental organisations are interacting with ethno-cultural groups in environmental activities.

\section{Main Concepts}

The following sections present general concepts that are relevant to this study. These concepts come from the three areas of research which this study intersects: the environmental movement, ethno-cultural diversity and volunteering.

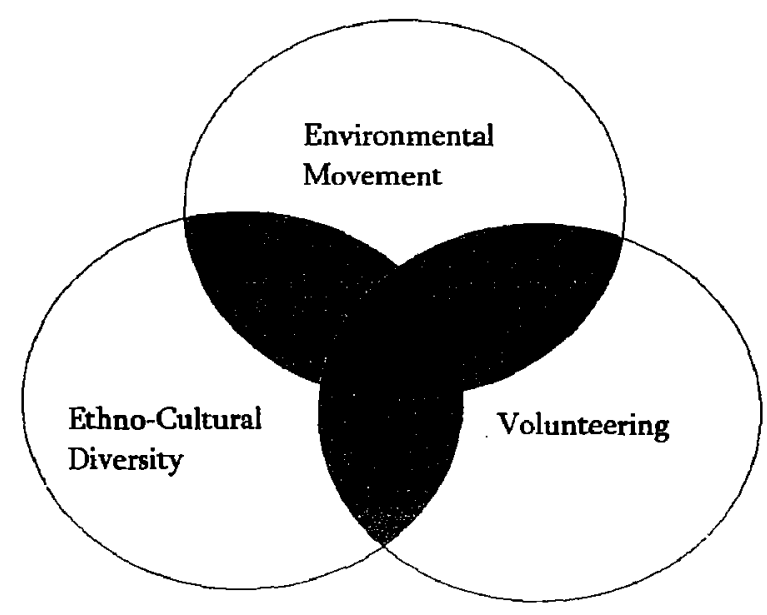

Figure 1: Scope of Background Research

These topics set the framework for this study. As shown in Figure 1, this study is represented by the black area at the centre of the diagram. In this chapter the three broad topics which are represented by the three large white areas labelled Environmental Movement, Ethno-cultural Diversity and Volunteering are discussed and defined. In the following chapter an enlargement of these topics is presented by reviewing literature relevant to the grey areas of the diagram which speaks to the overlaps of the three main study areas. 


\title{
The Environmental Movement
}

In this section, concepts and terms relevant to the environmental movement are presented. A definition of the environmental movement is given and other concepts such as environmental racism, environmental justice, civic environmentalism, citizen participation, environmental education and volunteer environmental stewardship are also discussed.

\section{Defining the Environmental Movement}

The environmental movement is also referred to as the green movement. It is defined in $A$ Feminist Glossary of Human Geography as:

\begin{abstract}
"A 'new social movement" which emerged in the 1960 s to oppose environmentally destructive practices. To some extent united by a focus on participative politics and decentralisation, its methods range from parliamentary tactics and traditional lobbying to symbolic protests and non-violent direct action. The movement is both international and local, diverse and internally conflictual. It includes Green parliamentary parties, environmental pressure groups, anti-nuclear campaigners, 'green consumerism', anti-roads protesters, conservationists, not-for-profit providers of recycling, insulation etc., animal liberationists, ecofeminist networks, organic farmers, indigenous people struggling to defend way of life, and urban ethnic minorities against environmental racism." (McDowell and Sharp, 1999: 73)
\end{abstract}

As the definition indicates, the environmental movement is made up of many diverse groups, each with its own cause and interest that links them to the larger environmental movement.

\section{Environmental Racism and Environmental Justice}

Focusing on specific groups, such as ethno-cultural groups within the environmental movement is not uncommon, especially from the environmental racism and environmental justice perspectives. Environmental racism "refers to any policy, practice or directive that differentially affects or disadvantages (whether intended or unintended) individuals, groups or communities based on race or color" (Bullard, 2000: 13). The plight of ethno-cultural minority groups rallying and lobbying against the placement of hazardous sites such as landfills, incinerators and

1 New social movements focus on the rights of women, blacks, people of colour, lesbians and gays, and deal with 
polluting industries in their neighbourhoods has been richly documented in the US context (Russel, 1989; Bullard, 1990; Bullard 1994; Camacho, 1998; Bullard 2000). Gosine (2003) notes that in Canada substantial scholarly work on environmental racism is still lacking compared to the US where environmental activists have "considered the influence of racism in environmental planning and policy since the early 1980s, when several communities of colour began to organize against the siting of toxic dumps in their neighbourhoods" (13). Environmental justice stems from environmental racism. "The Environmental justice framework incorporates other social movements and seeks to eliminate harmful practices (discrimination harms the victim) in housing, land use, industrial planning, health care and sanitation services" (Bullard, 2000: 5).

In October 1991, 17 Principles of Environmental Justice ${ }^{2}$ were adopted as part of the People of Colour Environmental Leadership Summit (ibid.: 3). "The environmental justice movement has changed the way scientists, researchers, policymakers and educators go about their daily work. This grassroots movement has redefined environment to include where people live, work, play and go to school, as well as how these things interact with the physical and natural world" (ibid.: $10)$.

\title{
Civic Environmentalism
}

Related to environmental justice is the concept of civic environmentalism. Hokenmaier (2005) defines civic environmentalism as:

\begin{abstract}
"a type of social action where citizens come together to solve environmental problems as a means to improve their communities. The goal is to ensure a sustainable community for future generations through participation in democratic processes."
\end{abstract}

Hokenmaier (2005) defines a sustainable community as a community which is able to meet its own needs without compromising the ability of future generations to meet their own needs. Communities that are sustainable are environmentally, economically and socially healthy. From

\footnotetext{
issues such as peace, disability, the environment, ecology and animal rights (McDowell and Sharp 1999: 257).
}

2 For a full description of the 17 Principles of Environmental Justice refer to (Bullard, 2000: 3). 
this perspective of sustainability, environmental issues are addressed holistically to include economic, political and cultural perspectives.

\section{Citizen Participation and Environmental Education}

Hokenmaier (2005) also notes that civic participation is an essential aspect of civic environmentalism. Without civic participation, solutions to environmental problems cannot be reached. Local knowledge and local input is important when addressing an environmental problem. Civic participation is further discussed later in this chapter, in the Volunteering section.

Environmental education is directly tied to civic environmentalism according to Hokenmaier (2005). The intent of environmental education is to raise awareness about environmental issues that will in turn lead to respect for the natural environment. Hokenmaier (2005) adds that environmental education helps citizens to feel more comfortable and interested in civic environmentalism. Environmental education and citizen participation are terms which are also found in the literature about volunteer environmental stewardship as detailed below.

\section{Volunteer Environmental Stewardship}

Citizen participation in the environmental movement can be called volunteer environmental stewardship (VES), which refers to "activities that contribute to the protection or restoration of a special area or feature of the natural environment by people who give their time and effort on a voluntary basis" (Lerner and Reid, 1993: 108).

These "activities" are further defined by being divided into two groups, basic and adjunct. Basic stewardship activities refer to advocacy, conservation, education, monitoring, preservation and restoration, while adjunct stewardship activities include fundraising, remedial action plan process, participation and research ${ }^{3}$. The above definition of volunteer environmental stewardship was developed and used by Lerner and Reid (1993) in their studies about local environmental groups in Ontario that carried out volunteer stewardship activities in the vicinity of the Great Lake Basin (Lerner and Reid, 1993: 105). 
Within the environmental movement, Lerner (1994) suggests that citizen activism occurs through environmental stewardship. Aside from the concrete results of monitoring, rehabilitation, research and other activities, stewardship groups are, according to Lerner (1994), a breeding ground for "environmental-vanguard qualities" which develop in its active members (14). These environmental vanguard or leadership qualities arise by personal commitment through personal involvement with the environmental stewardship group. In addition, because stewardship groups often seek help and funding from government sources, active members of stewardship groups become politicised and sophisticated by learning how to lobby, research, prepare briefs and interact with media to voice their opinions and concerns. Because of this not only do stewardship groups make a significant positive impact on local environments but they also serve as "an ethical and political training ground for the grassroots environmental vanguard, currently the strongest constituency for environmental interests" (Lerner, 1994: 14).

To highlight this point, Lerner (1994) uses the example of hobbyist or recreation groups, originally formed by people with common interest in a particular activity, that have been forced into the political domain to advocate for their leisure activities and distinctive places, which have been endangered by development and pollution. Furthermore, according to Lerner (1994), singleissue oriented environmental groups, will likely expand their interests to encompass broader environmental issues, as these groups are forced to engage in advocacy, education and monitoring.

\section{Ethno-cultural Diversity}

In this section, concepts and terms relevant to the study of ethno-cultural diversity are presented. The definition of the term ethno-culture is given. Other concepts such as multiculturalism, assimilation, integration and citizenship are also discussed. Definitions are also provided for the terms visible minorities and people of colour. 


\section{Defining Ethno-culture}

The word ethno-culture cannot be found in an ordinary dictionary. However, the meaning of this word can be discerned by breaking the word into two components - ethno and culture. According to the Online Etymology Dictionary, the word ethno originates from the Greek word ethnos, referring to "people, nation, class". The definition further states that the word ethno is used to form modern compound words like ethnology and ethnocentric. Such words were used as technical terms in the social sciences until the word ethno became more widely used in the latter half of the 20th century.

The word cultural stems from the word culture. "The word culture has many meanings. In the context of this study however, culture refers to:

"The way groups of people have learned to live by sharing certain historical experiences, including ideas, beliefs, values, knowledge, historical, geographical, linguistic, racial, religious, ethnic or social traditions. Culture is a complex and dynamic organization of meaning, knowledge, artlfacts and symbols that guide human behaviour, account for shared patterns of thought and action; and, contribute to human, social, and physical survival. Culture is transmitted, reinforced, passed on and changes" (Toronto, 1999: 3).

According to Waldron (2000) a culture is:

"(Something like) an enduring array of social practices, subsisting as a way of life for a whole people. Moreover a culture is not only an array of clubs and hobbies; it represents the heritage of a particular people's attempt to address and come to terms with the problems of social life problems that are serious and have to be addressed. $A$ culture will comprise a particular way of dealing, for example, with relations between the sexes, the rearing of children, the organization of an economy, the transmission of knowledge, the punishment of offences, and in general the vicissitudes that affect all the stages of human life and relationships from conception to the disposition of corpses, and from the deepest love to the most vengeful antipathies" (160-161).

The Glossary of Access and Equity Terms produced by the City of Toronto Committee on Access and Equity defines ethno-culture in the following way: 
"Every person belongs to an ethnic group and each identifies with some cultural heritage shared by people of certain national, religious and / or language backgrounds. The term ethnocultural refers an ethnic identity supported by cultural practice, tradition and institution. A group of people who believe they are ethnically and / or culturally distinct from other groups. For example, there are a wide variety of ethnocultural groups among people of African, Asian, European and indigenous Northern, Central and South American backgrounds in Canada" (Toronto, 1999: 6).

Given this definition, it is evident that the term ethno-cultural incorporates both one's visible characteristics such as hair, skin and eye colour, as well as non-visible characteristics such as beliefs and traditions.

\section{Multiculturalism}

In 1971, Canada became the first country to adopt multiculturalism as an official policy by affirming the dignity and value of all Canadian citizens, despite their race, ethnicity, language or religion (Canadian Multiculturalism, 2004). The Multiculturalism Policy of 1971 also affirmed the status of Canada's two official languages, English and French, and also confirmed the rights of Aboriginal peoples. It established programs and support services to ethno-cultural associations and individuals, to help them surmount barriers to their full participation in Canadian society.

In 1982, a new Canadian Charter of Rights and Freedoms was adopted, which officially endorsed Canada as a constitutional multicultural state. Section 72 of the Charter specifies that the courts must interpret the Charter "in a manner consistent with the preservation and enhancement of the multicultural heritage of Canada" (Canadian Multiculturalism, 2004)

Canada's multicultural population is the result of the country's aggressive immigration policy. "Today immigration has outpaced the natural birth rate, and accounts for $53 \%$ of the overall population growth" (Canadian Diversity, 2004). Canada is often touted as "the global village in one country" and this is reflected mainly in the country's large urban centres (ibid.). It is estimated that by 2006 , one in six Canadians will be a member of a visible minority group and that Canada's largest city, Toronto, will be the most multicultural city in the world. 
Multiculturalism has received criticism and is not always viewed in a positive light. Bissoondath's (1994) Selling Illusions: The Cult of Multiculturalism in Canada and Gwyn's (1995) Nationalism Without Walls: The Unbearable Lightness of Being Canadian are two examples of such criticisms. Both believe that multiculturalism promotes ethnic separatism and hinders integration. These claims are countered by Kymlicka (1998) who states "immigrant groups integrate more quickly and more effectively today than they did before the adoption of the multiculturalism policy, and they do so more successfully in Canada than in any other country that does not have such a policy" (8). Kymlicka (1998) adds the fact that ethno-cultural groups participate in politics without forming separate ethnic-based political parties is another indication that multiculturalism does not hinder integration in Canada.

\section{Assimilation, Integration and Citizenship}

The concepts of assimilation, integration and citizenship often accompany discussions about multiculturalism. Integration and assimilation are two terms that are often found in the literature about diversity and citizenship in Canada. It is important to distinguish between these terms because on the surface they may appear to be interchangeable. In differentiating between the two terms, Kymlicka and Norman (2000) state:

"Both involve fashioning a new transcendent identity - the identity of citizenship, or full equal membership in the state. And both seek to integrate people from various ethnic backgrounds into common social and political institutions. However, multicultural integration does not have the intent or expectation of eliminating other cultural differences between subgroups in the state. Rather, it accepts that ethnocultural identities matter to citizens, will endure over time, and must be recognized and accommodated with these common institutions. The hope is that citizens from different backgrounds can all recognize themselves, and feel at home, within such institutions" (Kymlick and Norman, 2000: 14).

Any discussion of assimilation and integration should also include a discussion about the meaning of citizenship. Kymlicka and Norman (2000) offer a tri-pronged approach, stating that citizenship can be thought of in terms of status, identity and activity: 
Status: This refers to one's status as a legal citizen, defined by an array of political and social rights and a small number of duties (e.g. to obey the law and pay taxes).

Identity: This refers to one's identity as a member of one or more political communities and to one's more particular identities based on class, race, ethnicity, religion, gender, profession, sexual preference etc.

Activity or Civic Virtue: This refers to one's active and productive participation in all aspects of society.

(Kymlicka and Norman 2000: 31)

\section{Visible Minorities, People of Colour, Immigrants and New Canadians}

The terms visible minorities and people of colour are often used in environmental justice and environmental racism literature. Although these two terms are closely related, it is important to distinguish between them. Definitions for each term are detailed below.

The term visible minority is used when referring to people who are visibly different from the members of the majority culture (Toronto, 1999: 4). Aside from being used in environmental racism literature, the term visible minority is also found in employment equity literature. Examples of visible minority groups include Blacks, Indo-Pakistanis, Chinese, Koreans, Japanese, South East Asians, Filipinos, other Pacific Islanders, West Asians, Arabs, Latin Americans, Aboriginals and people with multiple origins. The term racial minority can also be used when referring to visible minorities.

The term people of colour applies to members of racial minority groups who are non-Caucasian in race or non-white in colour who self identify or agree to be identified as part of that racial minority group. The term people of colour does not include Aboriginal people (Toronto, 1999: 11). In the Canadian context, people of colour, similar to the term visible minority, refers to people who, based on their physical characteristics, are subjected to discriminatory treatment. The difference between these two terms is that people of colour does not include Aboriginals whereas visible minority does include Aboriginals. This might lead to the notion that only people from non-Aboriginal ethno-cultural backgrounds are susceptible to racial discrimination, which is not true. 
The terms immigrant, new Canadian and newcomer are often used in the same context. The term immigrant means "one who moves from his / her place of origin to another country" (Toronto, 1999: 8) The terms new Canadian and newcomer are newer terms used in the literature which have a softer connotation than the term immigrant. The term new immigrant has previously been used by Statistics Canada when referring to immigrants who have been in Canada for five years or less. The terms recent immigrants and established immigrants have been used by Nevitte and Kanji (2003) in reference to immigrants who have been in Canada for ten years or less, or more than ten, years respectively.

\section{Census - Immigration Trends}

The 2001 Census can be used to reveal the ethno-cultural composition of Canada's population. Because the Census is conducted every ten years, with a partial census mid-way, it is also a useful tool to use when examining trends or changes in population demographics. During the first sixty years of the twentieth Century, immigrants to Canada were primarily from the United States and European countries such as England, Germany, Italy and the Netherlands (Badets, 2003: 20). Today, however this pattern of immigration has changed and the majority of Canada's immigrants arrive from Asian countries. As of 2001, 1.8 million people residing in Canada were immigrants who arrived during the past ten years. Immigrants born in Asia and the Middle East accounted for $58 \%$ of these immigrants followed by $20 \%$ born in Europe, $11 \%$ born in the Caribbean, South and Central America, 8\% born in Africa and 3\% born in the United States. The number of Asian immigrants has been increasing since the 1960s. In 1961 Asian immigrants accounted for $3 \%$ of all immigrants. In the $1970 \mathrm{~s}$, Asian immigrants accounted for $33 \%$ of all immigrants and in the 1980s Asian immigrants accounted for $47 \%$. In the 1990 s, the highest number of immigrants to Canada came from the People's Republic of China followed by India, the Philippines and Hong Kong.

A second trend is that immigrants to Canada are most attracted to large urban areas, namely Toronto, Vancouver and Montréal (Badets, 2003: 21). Of these three cities, Toronto attracted highest number of immigrants during the 1990 s. The 2001 Census indicates that $58 \%$ immigrants 
arriving in Canada during the 1970s settled in Toronto, Vancouver or Montréal. In the 1990s $73 \%$ of immigrants arriving in Canada settled in the same three cities. Because of the attraction to large urban areas, immigrants are accounting for an increasing proportion of the population in these areas. For example, in 2001, 44\% of people living in the Toronto Census Metropolitan Area (CMA) were foreign-born. This percentage of foreign-born residents exceeds that of other ethno-culturally diverse cities worldwide such as New York, Miami, Sydney and Los Angeles.

A third trend is that over the past 30 years, there has been a drastic change in the linguistic composition of immigrants coming to Canada. The 2001 Census indicates that $79 \%$ of immigrants arriving in Canada during the 1990s were allophones (people whose mother tongue is not French or English) whereas the percentage of allophones arriving in Canada during the 1970 s was only $49 \%$.

A fourth trend is that Canada's visible minority population is increasing. This trend is associated with the increase of Asian-born immigrants and decrease of European-born immigrants. In 1981, 1.1 million people identified themselves as being a member of a visible minority group. In 2001, this number grew to 4.0 million people (13\%). This represents a $5 \%$ increase in the visible minority population (Badets, 2003: 22). The visible minority population grew nearly six times faster than the total population and during 1991 to 2001, Canada's total population increased by $10 \%$ whereas the visible minority population increased by $58 \%$.

The Chinese are the largest visible minority group in Canada, followed by South Asians and Blacks. The 2001 Census breakdown of visible minorities in Canada is shown in Figure 2. 
Figure 2: Visible Minorities in Canada

\begin{tabular}{|l|c|}
\hline Visible Minority Group & $\begin{array}{c}\% \text { of Visible Minority } \\
\text { Population }\end{array}$ \\
\hline Chinese & $26 \%$ \\
\hline South Asians & $23 \%$ \\
\hline B]acks & $17 \%$ \\
\hline Filipino & $8 \%$ \\
\hline Arabs and West Asians & $8 \%$ \\
\hline Latin Americans & $5 \%$ \\
\hline Southeast Asians & $5 \%$ \\
\hline Koreans & $3 \%$ \\
\hline Japanese & $2 \%$ \\
\hline
\end{tabular}

\section{Volunteering}

In this section concepts and terms relevant to the study of volunteering are presented. Definitions of the terms volunteering and active citizenship are given. Other concepts such as civic participation and social capital are also discussed.

\section{Defining Volunteering and Active Citizenship}

Volunteering refers to "actions taken by people of their own free will in shaping their communities" (Advisory Board, 1997: 4). The act of volunteering is often referred to as active citizenship in third sector and citizenship literature. Active citizenship is "people accepting responsibility for, and participating in, civic affairs; and it is people helping others, both formally and informally" (Advisory Board, 1997: 4). Participation in volunteer environmental activities is a form of active citizenship, akin to Kymlicka and Norman's (2000) Civic Virtues.

Voluntary associations are an integral part of a society's social capital. Social capital can be defined as the reserves of social trust, norms and networks that people can rely upon to solve common problems. Networks of civic engagement can be formed by participating in neighbourhood associations, sports clubs, and cooperatives (Sirianni and Friedland, n.d.). 


\section{Civic Participation}

In its traditional form the term civic participation was associated with activities related to formal political rights and responsibilities such as voting, participating in electoral campaigns, communicating with politicians and other politically based actions. (Schugurensky, 2003). However, the term civic participation has recently been more broadly used to encompass other basic civic responsibilities such as being law abiding, keeping communities clean and safe, protecting the environment, assisting those in need of help, putting the common good ahead of self-interest, eradicating discrimination and injustice, and respecting the rights of others. Therefore the term civic participation, as it is used today goes beyond political participation to include active participation in civic life.

\section{Multiculturalism and Social Capital}

Johnston and Soroka (1999) studied Canadian social capital from a multicultural perspective examining data from the 1991 Canadian World Values Survey (WVS). On average, respondents, who were non-Caucasian (who were also primarily immigrants to Canada), had the fewest membership ties to 16 different types of associations, including political parties, social welfare groups and professional affiliations whereas the Caucasian respondents claimed the most.

Overall, this study sought to find out whether diversity is detrimental to social capital. Their analysis indicated that the most diverse provinces tended to be the most civic and "that the greater the difference between objective conditions in Canada and in the origin country and the greater the cultural distance traversed to get here, the more committed to Canada individuals tend to be" (Johnston and Soroka, 1999: 13). Their study also acknowledged that the "recency of arrival and cultural distance from the traditional 'core' Canadian ethnicities do not track linearly into weak associational involvement or into uncivic attitudes" (ibid.). They also suggest that diversity is not a barrier to social capital in Canada because the country's multicultural policy has made it easier to become a part of Canadian society.

Similar to Johnston and Soroka (1999), Aizlewood and Penakur (2003) studied the relationship between ethnicity and social capital in Canada. Using data from the 2000 Equality Security 
Community survey, Aizlewood and Pendakur (2003) also concluded that diversity is not detrimental to social capital in Canada because negative effects were not revealed across immigrant or visible minority groups. Their findings suggest that individual ethno-cultural characteristics do not significantly affect scores on standard social capital measures. They "speculate that in Canada, where community size, diversity, wealth and education are so closely and positively correlated, an urban lifestyle, or 'city effect' may be a more accurate predictor of civic attributes and behaviours" (Aizlewood and Pendakur, 2003: 2).

Bridging and bonding are terms which are used in social capital literature to describe the types of associations or networks individuals may have. Bonding "brings together people who share common socio-demographic characteristics (including ethnicity)" (Tossutti, 2003: 17). Bridging "refers to networks whose participants are drawn from dissimilar backgrounds" (ibid.). For example, a church group helping its new immigrant congregants can be referred to as bonding. An example of bridging would be an environmental group working with the new immigrant congregants of various church groups on an environmental project. In terms of this study, the interactions between ethno-cultural and environmental groups are a form of bridging because they provide a venue in which ethno-cultural groups, the new immigrants in particular, can meet other Canadians.

\section{Discussion and Summary of Key Points}

This study pertains to the environmental movement in Toronto. This study was not undertaken specifically from an environmental racism or environmental justice perspective. It was undertaken as pilot study with the intent of gathering exploratory information to cast light on how environmental groups in Toronto are engaging ethno-cultural groups and to learn how ethno-cultural diversity has influenced environmental activities in Toronto.

The purpose of this chapter was to set the basic framework for this study by presenting general concepts in each area of research this study intersects. There areas were the environmental movement, ethno-cultural diversity and volunteering. The preceding sections revealed that there 
are connections and overlaps between these three areas. For example, civic participation is a term that is related to volunteering but which is also found in environmental literature as being related to volunteer environmental stewardship. Environmental education, which is an essential part of civic environmentalism, is also used as a classification of basic volunteer environmental stewardship.

Important distinctions were also drawn between the terms visible minorities, people of colour and ethno-cultural groups. The classification of visible minorities and people of colour are based on physical attributes such as skin colour whereas ethno-cultural classifications are based upon physical attributes as well as unfixed traits such as customs and beliefs. The terms bridging and bonding, as they relate to social capital were defined and based on these definitions the interactions between environmental and ethno-cultural groups can be classified as bridging.

Immigration trends in Canada were also detailed. These include the facts that: (1) currently the majority of immigrants come to Canada from Asian countries; (2) immigrants prefer large urban centres such as Toronto, Vancouver and Montreal; (3) immigrants speak languages other than English and French; and (4) the visible minority population is increasing.

According to the City of Toronto website, $49 \%$ of Toronto's population was born outside of Canada and Toronto accounted for $48.7 \%$ of the GTA's ${ }^{4}$ population. In 2001 Toronto received $57.8 \%$ of the total immigrants in the GTA and $60.4 \%$ of all GTA residents belonged to a visible minority group. In keeping with Canada's policy on multiculturalism and preference for integration of its citizens into Canadian society, it would follow that immigrants to Canada learn to adapt to Canadian society by incorporating their own culture with the new way of life they have been introduced to in Canada. Over 100 languages and dialects are spoken in Toronto and of the total residents in Toronto, more than one third speak a language other than English at home.

4 GTA stands for Greater Toronto Area. It refers to The City of Toronto and 4 surrounding regions - Halton, Peel, York and Durham. 
If, as Kymlicka, Norman and others believe, multiculturalism does not hinder integration, it would follow that ethno-cultural groups as active citizens in all aspects of Canadian society should also be a part of the environmental movement. In keeping with Canada's preference for the integration of ethno-cultural groups into society, it would follow that environmental groups, should not only be actively engaging ethno-cultural groups in environmental activities but also attempting to learn from these ethno-cultural groups, their environmental values and traditional forms of environmentalism.

Building on the concepts presented in this chapter the following chapter will focus on literature that is more specific to the research question. 



\section{Chapter II: Enlargement}

Building on the general concepts presented in the previous chapter, this chapter provides an examination of literature that is more specific to the research question. To narrow in on research that is relevant to the research question the overlapping grey sections (labelled one, two and three) of Figure 3 are the focus of this chapter. Three main headings namely - (1) Environmental Movement and Volunteering, (2) Volunteering and Ethno-cultural Diversity and (3) Ethnocultural Diversity and the Environmental Movement - are used to present this literature.

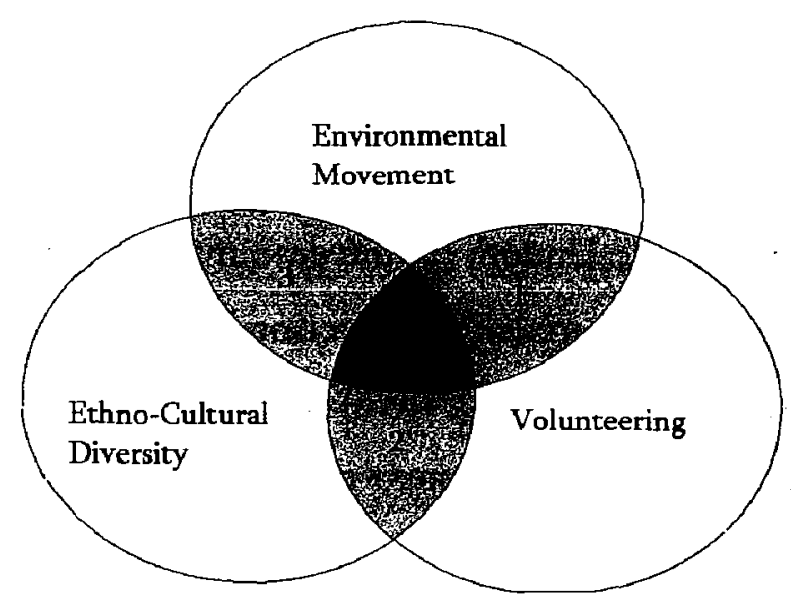

Figure 3: Scope of Literature Review

\section{The Environmental Movement and Volunteering}

The previous chapter established that civic participation and active citizenship within the environmental movement can be referred to as volunteer environmental stewardship (VES). Aside from the works of Lerner (1993 and 1994) and Lerner and Reid (1993) studies that examine volunteer environmental stewardship, especially in the Canadian context are limited. This section speaks to the benefits, motivations and barriers which are specific to participating in volunteer environmental activities. General motivations and barriers to volunteering are described in the 2000 National Survey of Giving Volunteering and Participating (NSGVP), which will be discussed later in this chapter. 


\section{Volunteer Motivations in Environmental Activities}

Westphal (1993) found that volunteers involved in the restoration of savannah ecosystems did so for three key reasons. Volunteers (1) were searching for an improved connection with nature; (2) wanted to do something tangible to help the environment; and (3) recognised the aesthetic and emotional benefits of nature. Westphal (1993) adds that understanding the volunteers' underlying values and motivations is important in that it can help with outreach programming and the recruitment of new volunteers.

Miles, Sullivan and Kuo (1998) studied the psychological benefits of participation based on the survey responses of 263 ecological restoration volunteers in Chicago. Examining the benefits derived by these volunteers can be used to reveal why these volunteers contribute their time and effort to restoration work (Miles, Sullivan and Kuo, 1998: 28). They note that the benefits experienced by volunteers are often dependent on the amount and type of volunteer participation. Their study revealed that partaking in meaningful action and fascination with nature were the most common reasons volunteers had for being involved in restoration activities. Participation in terms of broadening one's experiences was the next most popular benefit cited by volunteers.

Although the motivation indicators used across studies varies in terms of syntax, common motivations for volunteering in environmental activities have emerged from different settings. For example, Donald (1997) focused on the Task Force to Bring Back the Don in Toronto whereas Ryan, Kaplan and Grese (2001) focused on volunteers from Adopt-a-Stream programs, the municipal parks department and the state chapter of national conservation, all in Michigan. Schroeder (2000) did a content analysis of 27 newsletters from stewardship groups involved in restoring prairie and savannah ecosystems. All of these studies yielded common motivations for volunteering in stewardship groups such as that the volunteers had the opportunity to help the environment, learn something new and develop new friendships. The ability to reflect upon nature was also a common motivation found in all but Donald's (1997) study.

However, of these studies, Donald's (1997) is the only one that provided ethno-cultural information about the survey respondents. She notes that only $4 \%$ of the respondents identified 
themselves as being from a visible minority group. She also mentions that traditional environmental groups such as the Task Force have attempted to make their organisation accessible to visible minority groups by advertising in ethnic minority newspapers. No further details were provided by Donald that would indicate whether or not interactions between the Task Force and ethno-cultural groups occurred because of this.

In volunteer (third sector) studies, most theories about volunteer motivations are quite complex and rely heavily on statistical analysis. However, the common volunteer stewardship motivations noted above can be paralleled to Clary and Snyder's (1999) Volunteer Functions Inventory (VFI). The VFI has six main functions that are fulfilled by volunteering. These are: Values: volunteering to act on values such as humanitarianism; Understanding: volunteering to learn more or use skills that are unused; Enhancement: volunteering to grow and develop psychologically; Career: volunteering to career-relevant experience; Social: volunteering to strengthen social ties; Protective: volunteering to decrease negative feelings.

\section{Barriers to Volunteering in Environmental Activities}

The studies discussed above did not pay particular attention to the motivations and barriers to volunteering in environmental activities which may be experienced by ethno-cultural groups, specifically new Canadians ${ }^{1}$. Barriers that may be experienced by new Canadians were however developed by the Toronto and Region Conservation Authority (TRCA), as an outcome of their Community Development for Multicultural Stewardship (CDMES) program, which specifically targeted different ethno-cultural groups for participation in volunteer environmental stewardship activities from 1998-2000. These barriers are described in Figure 4.

1 New Canadian / New immigrant refers to immigrants that have been in Canada for 5 years or less. 
Figure 4: Barriers and Responses to Volunteering

\begin{tabular}{|c|c|}
\hline Barrier & Response \\
\hline \multirow{3}{*}{ Language } & Provide translators at events. \\
\hline & Translate literature. \\
\hline & Make displays with simple text and captivating graphics. \\
\hline \multirow{2}{*}{ Accessibility to program site } & Provide free or subsidised transportation for large events. \\
\hline & $\begin{array}{l}\text { Choose safe project sites that are close by and inexpensive or } \\
\text { free to access so participants can visit the site on their own. }\end{array}$ \\
\hline \multirow{2}{*}{$\begin{array}{l}\text { Little or no contact with } \\
\text { environmental groups }\end{array}$} & $\begin{array}{l}\text { Search for new Canadian groups and approach them. Do not } \\
\text { wait for them to find you. Access settlement agencies, the } \\
\text { United Way, school boards, directories, colleagues and } \\
\text { neighbours for information about different groups. }\end{array}$ \\
\hline & $\begin{array}{l}\text { Visit places where new Canadians meet such as churches and } \\
\text { temples, and attend their events when invited. }\end{array}$ \\
\hline \multirow[t]{2}{*}{$\begin{array}{l}\text { Settlement issues take } \\
\text { priority }\end{array}$} & $\begin{array}{l}\text { Many new Canadians struggle to meet their basic needs and } \\
\text { find homes and employment. Be respectful and aware of this } \\
\text { by making it convenient and inexpensive for them to attend a } \\
\text { program and / or adopt environmentally-friendly practicies. }\end{array}$ \\
\hline & $\begin{array}{l}\text { Provide experiences and training that will help new Canadians } \\
\text { find employment. }\end{array}$ \\
\hline \multirow{3}{*}{ Lack of resources } & $\begin{array}{l}\text { Partner with other groups and agencies to increase knowledge } \\
\text { and resources and to achieve common goals. }\end{array}$ \\
\hline & Offer free technical assistance and educational resources. \\
\hline & $\begin{array}{l}\text { Inform new Canadian groups about available funding and } \\
\text { help them secure funding for their own enviornmental } \\
\text { projects. }\end{array}$ \\
\hline
\end{tabular}

Source: Community Development for Multicultural Environmental Stewardship Project

A 10-minute video titled Human Connections (2000) was also produced by the TRCA to document how it encouraged ethno-cultural groups to participate in its environmental stewardship activities. The video highlights some of the CDMES projects and also reiterates the 
barriers detailed in the chart above. It also provides four additional suggestions that can be used to plan and implement environmental activities with ethno-cultural groups:

1. Personal contact with local community leaders is useful to get 'an in' with ethnocultural groups.

2. Information about the environmental activity should be specific and culturally relevant to the targeted ethno-cultural group.

3. Local ethno-cultural newspapers and radio stations can be used to raise awareness about an activity or event that is targeted to specific communities.

4. Environmental groups can visit local ESL and other immigrant or settlement centres to ask for volunteers and raise environmental awareness.

\section{Volunteering and Ethno-cultural Diversity}

This section presents literature that is relevant to both volunteering and ethno-cultural diversity. The National Survey of Giving, Volunteering and Participating (NSGVP), Census 2001 Immigration Trends and the Ethnic Diversity Survey (EDS) are discussed. A profile of Ontario's volunteers is also provided along with a discussion about immigrants and volunteering.

\section{The National Survey of Giving, Volunteering and Participating}

The 2000 National Survey of Giving, Volunteering and Participating (NSGVP) can be used as an indicator of civic activities in Canada and Ontario. The Survey is also useful in determining the motivations volunteers had for volunteering and their demographic composition.

Twelve different organisation classifications were used in the 2000 NSGVP to gain a sense of which types of organisations Canadians tended to volunteer for. These categories as well as the percentages of Canadians volunteering for these types of organisations are noted in Figure 5. 
Figure 5: Where Canadians Volunteer

\begin{tabular}{|l|c|}
\hline \multicolumn{1}{|c|}{ Organisation Type } & $\begin{array}{c}\% \text { of Canadians } \\
\text { Volunteering }\end{array}$ \\
\hline Arts, Culture and recreation organisations & $8 \%$ \\
\hline Social service organisations & $7 \%$ \\
\hline Religious organisations & $6 \%$ \\
\hline Education and research organisations & $5 \%$ \\
\hline Health organisations & $5 \%$ \\
\hline Development and housing organisations & $2 \%$ \\
\hline Law, advocacy and politics organisations & $\mathbf{1 \%}$ \\
\hline Environment organisations & $<1 \%$ \\
\hline Philanthropic and volunteerism promotion organisations & $<1 \%$ \\
\hline Business and professional associations and unions & $<1 \%$ \\
\hline International organisations & $<1 \%$ \\
\hline Other organisations & $<1 \%$ \\
\hline (Lasby and McIver, 2004: 5) & \\
\hline
\end{tabular}

Generally speaking, the types of organisations for which Canadians tended to volunteer varied with demographics. For example, those aged 35-45 years were more likely to volunteer for Arts, culture and recreation organisations whereas older Canadians were more likely to volunteer for religious organisations (Lasby and McIver, 2004: 21). Younger Canadians tended to volunteer more for Education and research organisations and volunteering in general was highest among those Canadians with higher levels of education and higher household incomes.

Volunteers' motivations were also explored to learn about why volunteers chose to volunteer for these organisations. Respondents of the 2000 NSGVP were given 8 possible reasons to explain why they volunteered, as shown in Figure 6. 


\section{Figure 6: Motivations for Volunteering}

\begin{tabular}{|l|c|}
\hline \multicolumn{1}{|c|}{ Motivations for Volunteering } & \% of Canadians \\
\hline To help a cause you believe in & $\mathbf{9 5 \%}$ \\
\hline To use your skills and experiences & $\mathbf{8 1 \%}$ \\
\hline Personally affected by the cause of an organisation & $69 \%$ \\
\hline Explore your own strengths & $57 \%$ \\
\hline Because your friends volunteer & $30 \%$ \\
\hline Fulfil religious obligations / beliefs & $26 \%$ \\
\hline Improve your job opportunities & $23 \%$ \\
\hline Required to volunteer & $\mathbf{8 \%}$ \\
\hline (Lasby and McIver, 2004: 6) & \\
\hline
\end{tabular}

Barriers to volunteering were also explored as part of the 2000 NSGVP. Respondents were asked whether any of 11 possible barriers prevented them from volunteering more time. The results are detailed in Figure 7.

Figure 7: Barriers to Volunteering

\begin{tabular}{|l|c|}
\hline Barriers to Volunteering & $\%$ of Canadians \\
\hline Do not have any extra time & $76 \%$ \\
\hline Unwilling to make year-round commitment & $34 \%$ \\
\hline Have already made a contribution & $29 \%$ \\
\hline Give money instead of time & $24 \%$ \\
\hline No one has personally asked & $17 \%$ \\
\hline Health problems / unable & $16 \%$ \\
\hline Cost of volunteering & $13 \%$ \\
\hline Do not know how to get involved & $10 \%$ \\
\hline Bad previous experience with volunteering & $8 \%$ \\
\hline Legal concerns & $5 \%$ \\
\hline (Lasby and McIver, 2004: 7) & \\
\hline
\end{tabular}

Recruitment methods for volunteering were also explored as part of the 2000 NSGVP, as described in Figure 8. 


\section{Figure 8: Volunteer Recruitment Methods}

\begin{tabular}{|l|c|}
\hline \multicolumn{1}{|c|}{ Recruitment Method } & $\%$ of Canadians \\
\hline Organisation asked & $38 \%$ \\
\hline Member of organisation & $21 \%$ \\
\hline Approached organisation on own & $21 \%$ \\
\hline Child involved & $15 \%$ \\
\hline Friend asked & $13 \%$ \\
\hline Nominated to volunteer & $5 \%$ \\
\hline Responded to public appeal & $4 \%$ \\
\hline Boss asked & $4 \%$ \\
\hline Other & $7 \%$ \\
\hline (Lasby and McIver, 2004: 8) \\
\hline
\end{tabular}

Age is a factor that affects volunteering in terms of both motivations and barriers. Younger volunteers were more likely to volunteer because they wanted to explore their strengths and improve their job prospects. Religious motivations were prominent for volunteers aged 65 and over at a rate of $50 \%$ whereas younger age categories (between 15-54) responded to the same category at rates of $25 \%$ or less. Volunteers between ages $55-64$ responded at a rate of $32 \%$.

\section{A Profile of Ontario's Volunteers}

The 2000 NSGVP provides information that is specific to Ontario that informs about what Ontario's volunteers do, where they volunteer and how they became involved in volunteering. According to the 2000 NSGVP, $25 \%$ of Ontario residents volunteered through a charitable or non-profit organisation (Canadian Centre for Philanthropy, 2003: 1). While this value is $7 \%$ less than the same value in 1997, the 2000 NSGVP indicates that Ontario volunteers spent more time volunteering on average in 2000 than in 1997. In 2000, Ontarians spent an average of 165 hours volunteering, whereas in 1997, Ontarians spent on average 13\% fewer hours volunteering or 146 hours.

Volunteers in Ontario engaged in many different volunteer activities, as summarised in Figure 9. 
Figure 9: Volunteer Activities - Ontario

\begin{tabular}{|l|c|}
\hline \multicolumn{1}{|c|}{ Volunteer Activity } & $\begin{array}{c}\% \text { Volunteers in } \\
\text { Ontario }\end{array}$ \\
\hline Helping organise activities & $56 \%$ \\
\hline Canvassing, campaigning or fundraising & $41 \%$ \\
\hline Serving as a board or committee member & $40 \%$ \\
\hline Teaching or coaching & $30 \%$ \\
\hline Providing information or educating others & $30 \%$ \\
\hline Consulting, executive or office work & $28 \%$ \\
\hline Collecting, serving or delivering food or goods & $25 \%$ \\
\hline Providing care or support including counselling & $25 \%$ \\
\hline (Canadian Centre for Philanthropy, 2003: 1 ) \\
\hline
\end{tabular}

Volunteers in Ontario cited that the most common reason for getting involved in volunteering was that they were asked by in the organisation (32\%). Only $16 \%$ responded that they became involved by approaching the organisation on their own. These and other reasons for becoming involved in volunteers are summarised in Figure 10.

\section{Figure 10: Reasons for Volunteering - Ontario}

\begin{tabular}{|l|r|r|}
\hline \multicolumn{1}{|c|}{ Reason for getting involved } & \% of Ontario Volunteers & \\
\hline Organisation asked & $32 \%$ & \\
\hline Approached organisation on own & $16 \%$ & \\
\hline Member of organisation & $14 \%$ & \\
\hline Child or spouse involved & $11 \%$ & \\
\hline Asked by friend or relative & $9 \%$ & \\
\hline Nominated by someone & $5 \%$ & \\
\hline Asked by boss / employer & $3 \%$ & \\
\hline (Canadian Centre for Philanthropy, 2003: 2) & \\
\hline
\end{tabular}

\section{Immigrants and Volunteering}

The 2000 NSGVP also collected information specific to immigrants to Canada. Approximately $16 \%$ of those surveyed were or had been landed immigrants in Canada (Canadian Centre for Philanthropy, 2004a: 2). Immigrants to Canada were slightly less likely to volunteer compared to Canadians in general ( $21 \%$ vs. $27 \%$ respectively). When they did volunteer, immigrants volunteered fewer hours than Canadians did (144 hours vs. 162 hours per year). 
However, the number of hours volunteered and likelihood of volunteering increased with the length of time immigrants were in Canada. The 2000 NSGVP was able to show this by distinguishing between established and recent immigrants. Established immigrants were those who immigrated during or before 1979 whereas recent immigrants were those who immigrated during or after 1980. Established immigrants volunteered at a rate of $25 \%$ as compared to recent immigrants who volunteered at a rate of $17 \%$. Recent immigrants volunteered on average, 102 hours per year whereas established immigrants volunteered $42 \%$ more, at 177 hours.

Compared to Canadians, immigrants volunteered more of their time to religious organisations. Over one-fourth (28\%) of the hours volunteered by immigrants was for religious organisations as compared to Canadians in general who volunteered only $16 \%$ of their volunteer hours to religious organisations. Established immigrants were also more likely than both recent immigrants and Canadians to volunteer for an organisation as the result of knowing someone who was personally affected by the cause the organisation supported. Recent immigrants cited not being asked (48\%) and not knowing how to get involved (41\%) as their predominant reasons for not partaking in volunteer activities.

Aside from distinguishing between established and recent immigrants, the 2000 NSGVP does not further breakdown the results into different ethno-cultural groups. Based on the findings of these studies, the need for environmental groups to engage, interact with or acknowledge different ethno-cultural groups in order to carry out environmental activities effectively seems essential. This would be especially true for Toronto, because it "is by far the most diverse Census Metropolitan Area (CMA) in Ontario" (Ontario, 2003: 1). In 2001, 36.8\% of Toronto's population identified themselves as visible minorities and during the 1990s, Toronto received $43 \%$ of Canada's new immigrants (Badets, 2003: 21)

\section{Ethnic Diversity Survey}

Statistics Canada's Ethnic Diversity Survey (EDS) examined Canada's ethno-cultural groups using a tri-pronged approach. Each area of analysis was broken into three different generation categories as well as by ethnic group. The three generation categories were: 
- The first generation - who are themselves foreign-born

- The second generation - who are Canadian-born and have at least one parent who was born outside Canada

- The third generation or more, who are the children of Canadian-born parents and possibly Canadian-born grandparents

Areas of analyses included an examination of the "level of attachment that people in the different generations and ethnic groups have to their own ethno-cultural backgrounds and to the broader Canadian society...The survey covered topics such as ethnic or cultural ancestry and identity, background, language use, social networks, interaction with others and civic participation" (Canada, 2003: 1). The EDS was conducted between April and August 2002 and included 42,500 respondents aged 15-years or older from Canada's 10 provinces. Canada's Aboriginal peoples were not included in the target population of the EDS, as a previous Statistics Canada survey was specifically designed and targeted to this group.

The EDS revealed that $50 \%$ of the population has a strong sense of belonging to their ethnic group and this varied by ethnic group as shown in Figure 11 .

Figure 11: Sense of Belonging by Ethnic Group

\begin{tabular}{|c|c|}
\hline Ethnic Group & $\begin{array}{c}\text { \% Sense of belonging to ethnic } \\
\text { group }\end{array}$ \\
\hline Filipinos & $78 \%$ \\
\hline East Indians & $65 \%$ \\
\hline Portuguese & $65 \%$ \\
\hline French Canadians & $60 \%$ \\
\hline Chinese & $58 \%$ \\
\hline Italians & $56 \%$ \\
\hline (Canada, 2003: 8) \\
\hline
\end{tabular}

This variation in sense of belonging among ethnic groups could be related to the extent to which the group is made up of new immigrants to Canada and of people who have been here for many generations. Generally, the first generation (57\%) had a higher sense of belonging than the 
second and third or more generations ( $47 \%$ and $48 \%$ respectively). Furthermore, within the first generation, the more recently people had arrived in Canada, the more likely they were to report a stronger sense of belonging to their ethnic group. For example, $62 \%$ of those who arrived in Canada since 1991 reported a strong sense of belonging to their ethnic group as compared to $48 \%$ of those who arrived in Canada before 1961. This can be explained by the Longitudinal Survey of Immigrants to Canada which states that family and friends play an important role in the initial settlement of new immigrants in Canada and that it is likely that these family and friends are of the same ethnic or cultural background and because of this, the first generation keeps stronger ties to their ethnic group upon arrival in Canada.

Similarly, the first generation was more likely than second and third or more generation groups to indicate that ethnic customs and traditions were very important. For example, $68 \%$ of the first generation who rated their ancestry highly reported that it was important to carry on the customs and traditions of at least one of their ancestral groups. Of the first generation respondents, a general trend was that the more recently one had arrived in Canada, the more likely they were to report that their customs and traditions were very important to them. Some ethnic groups, regardless of length of time in Canada also tended to cite that their customs and traditions were important to them, as shown in Figure 12.

\section{Figure 12: Importance of Customs and Traditions by Ethnic Group}

\begin{tabular}{|l|c|}
\hline \multicolumn{1}{|c|}{ Ethnic Group } & $\begin{array}{c}\text { \% Reporting customs / } \\
\text { traditions as very } \\
\text { important }\end{array}$ \\
\hline Punjabis & $92 \%$ \\
\hline Greeks & $81 \%$ \\
\hline Filipinos & $79 \%$ \\
\hline Jamaicans & $76 \%$ \\
\hline (Canada, 2003: 10$)$ & \\
\hline
\end{tabular}

The Survey also examined how respondents were participating in groups or organisations during the 12 months before the survey was administered. The EDS measured membership and participation in groups such as sports and hobby clubs, community organisations, and ethnic associations. The first generation had the lowest rates of participation in groups. However, 
participation in groups increased with time lived in Canada. For example, 34\% of the first generation who arrived in Canada in the 1990s cited they had been members of a group or that they been part of at least one group activity in the previous year. This number increased to $37 \%$ with those who had arrived in Canada during the 1980s and again increased to $41 \%$ with those who had arrived in Canada before 1981. This has been attributed to the fact that as new immigrants to Canada, the first generation needs to adjust to their new country, make new friends, establish new networks, and settle into jobs and the community where they live.

The EDS also revealed that the first generation respondents tended to participate at a higher rate in ethnic or immigrant associations than the second or third or more generation respondents. These findings are consistent with the Longitudinal Survey of Immigrants to Canada, which notes that a network of family and friends played an important role in the settlement and integration of new Canadians. Newcomers to Canada may also be participating in ethnic or immigrant organisations because such organisations sometimes provide settlement and support services to new immigrants.

The EDS also examined how people in Canada are coping with integration and inclusion in Canadian society. The EDS found that $78 \%$ of the respondents reported that they never felt uncomfortable or out of place because of their ethnicity, culture, race, skin colour, language, accent or religion. Those who felt uncomfortable or out of place only rarely accounted for $13 \%$ of the population. Those who reported that they felt uncomfortable or out of place sometimes, most of the time or all of the time because of their ethno-cultural characteristics accounted for $10 \%$ of the population. Of this $10 \%$ of the population, $8 \%$ reported they felt out of place some of the time and about $2 \%$ reported feeling out of place most or all of the time due to their ethnocultural traits.

Canada's visible minorities were more likely than other groups to feel out of place or uncomfortable in Canada because of their ethno-cultural traits. The majority of the visible minorities included in the EDS were found in the first generation respondents (84\%), followed by the second generation (14\%), followed by the third or more generation $(2 \%)$. 
Of the visible minorities included in the EDS, $24 \%$ reported that they felt uncomfortable or out of place because of their ethno-cultural traits all, most or some of the time as compared to only $8 \%$ of non-visible minorities who felt the same way.

\section{Ethno-cultural Diversity and the Environmental Movement}

This section presents literature that speaks to the interplay of ethno-cultural diversity and the environmental movement. The previous chapter established that ethno-cultural groups are active within the environmental movement, specifically within the environmental justice and environmental racism frameworks. The following sections reveal that ethno-cultural groups have different environmental concerns and attitudes and because of this environmental discourse should be broadened to include these different viewpoints.

\section{Environmental Concern and Culture}

Kato (2002) says that environmental discourse which has often been assumed to be universal needs to be challenged to further develop environmental ideologies in today's increasingly diverse social contexts. Kato (2002) emphasizes the importance of cross-cultural awareness in environmental discourse which brings forth alternate perspectives to the environmental movement's traditional or mainstream viewpoints.

Using the example of whaling in Japan, which has been viewed in Western cultures as ecologically ignorant and barbaric, Kato (2002) says that there is a clear difference in cultural values attached to whales between Eastern and Western cultures. She adds that people from different cultures express their values differently and this applies equally to environmental values. Without specifically condoning or condemning the practice of whaling, Kato (2002) states that although the practice of whaling is viewed by Western cultures in a negative way, it should not be assumed that Asian communities do not care for the environment. Rather, Kato (2002) suggests that cross-cultural awareness or alternative environmental viewpoints are necessary to develop an interdisciplinary understanding of sustainability. She adds that social 
and cultural aspects specific to the local context should be incorporated into environmental management and education, which will enhance the development of environmental discourse.

Kalland and Persoon (1998) suggest that diversity exists not only in backgrounds, histories, strategies and ideologies but also in definitions of a "better environment", which challenges the existing definition of sustainability and the extent to which it may be viewed as universal. In response to this, Yechen (2000) suggests to think globally and locally and to act locally. Doing this will place value on different sources of traditional environmental knowledge, local understanding and local experiences to enhance environmental debates.

Ponting (1991) notes that all cultures that exist today address the issue of one's relationship with the natural environment just as all cultures have rules for social interaction. Schultz (2002) says that because different cultures have different norms, values and beliefs, the way environmental problems are understood and addressed occurs through one's cultural filter.

The previous chapter established that more than $45 \%$ of Toronto's population was born outside of Canada, that the number of immigrants coming to Canada exceeds the country's natural birth rate and the country's visible minority population is increasing. When combining these facts with the viewpoints detailed above, the need for environmental organisations to encourage the participation of ethno-cultural groups in their activities seem essential.

\section{Ethno-cultural Groups and the Environmental Movement}

According to Gosine's Myths of Diversity (2003) it is a myth to consider that the environmental movement is white. He adds that although the people of colour might not occupy leadership positions or jobs in the green movement, that fact does not mean that people of colour do not participate in the movement. In Toronto's case, he points out that immigrants bring with them environmental traditions from their own cultures and consider themselves to be environmentalists. That people of colour do not care about environmental issues or have other things to worry about is another myth challenged by Gosine (2003). He states that this is not the case, rather "that people of colour living in North America clearly haven't become aware of 
environmentalist issues" because they have not been framed in ways that they can relate to (Gosine, 2003: 14).

This point is echoed by Taylor (1993) who suggests that there are many environmental groups serving people of colour that have emerged within the environmental justice movement which is an indication to the mainstream environmental movement that people of colour are interested in environmental issues but that people of colour have remained outside of the mainstream environmental movement because of the way in which environmental issues were framed, the types of issues that were addressed and ways that these issues were addressed. M. Ann Phillips, a member of Women's Health in Women's Hands, a community health centre in Toronto that serves immigrants, refugees and low-income black women and women of other ethno-cultural groups suggests that "people of colour have always been environmentalists. But many of them don't see it as just taking care of 'the environment': they see it as taking care of their communities and themselves. For many it's about living practices, not joining a club" (Gosine, 2003: 15).

While the social and economic characteristics of ethnic groups and immigrants are well documented in the literature research focusing on their environmental interests, beliefs and behaviours is very limited in the Canadian context. In an attempt to fill this research gap, a survey-based study done in 2001, by the Sustainability Network, sought to "explore Ontario's ethno-cultural communities' interest in environmental issues" (Mitra, 2001: 8). From this study a directory was produced that listed ethno-cultural groups in Ontario that expressed an interest in environmental action and it was hoped that partnerships would form between these environmental groups and ethno-cultural groups.

This directory also briefly summarised four examples where environmental and ethno-cultural groups had worked together to carry out volunteer environmental stewardship activities in Toronto. The projects highlighted were the Chinese Environmental Ambassadors Project, the Integrated Neighbourhood Tour Project, Building a Sustainable Community in the New Millennium and the Community Development for Multicultural Environmental Stewardship Program. However, because this directory was only produced once, no follow-up studies were 
conducted to track the progress, status or outcomes of these interactions.

Other environmental directories such as The Green List (2002) highlight the different environmental groups within Canada. However, this directory does not convey specific information about the interactions that these environmental groups have had with ethno-cultural groups. Another directory published in 2000 called People of Color Environmental Groups, is similar to that produced by the Sustainability Network. It lists over 400 people of colour, legal groups and resource groups from the USA, Puerto Rico, Canada and Mexico. "The directory is designed as a planning, organizing, networking and community empowerment tool" (Bullard, 2000: 1). Similar to the purpose of the Sustainability Network's directory, this directory was also intended to help ethno-cultural and environmental groups organise and form partnerships, although in both cases, it is unclear whether this goal was actually achieved. For Ontario, the People of Color Environmental Groups directory lists 22 environmental groups whose constituents include Native-Americans, Blacks and multi-ethnic groups. While this directory serves a good source of condensed information, it does not provide detailed information about what types of environmental activities their ethno-cultural constituents are involved in. Also, it does not give any indication as to whether the organisations mentioned have worked with each other or other groups not listed in the directory to carry out environmental activities.

\section{The Environmental Movement and Participation of Ethno-cultural Groups in Canada}

Specific to Toronto, cases of environmental and ethno-cultural group interactions have been documented to a limited extent. A 1995 article featured in Alternatives briefly highlights the work of immigrants on environmental issues in Canada. Yuga Juma Onziga who worked for Toronto's Environmental Centre for New Canadians (ECENECA), assists new Canadians become attuned to environmental issues ranging from the need to dress warmly in cold weather to the dangers of environmental pollution (Pickering, 1995: 13). Onziga, grew up in rural Uganda and believes that different cultural experiences can provide innovative and creative perspectives and can help find solutions to environmental problems facing all Canadians, especially those immigrants from rural areas where such practices are already integrated into 
community life. ECENECA focused on translating environmental information, normally only available in English and French, into Somali, Amharic, Swahili and Spanish.

Ashraf Karimi, another new Canadian featured in Pickering's (1995) article, works with Toronto's Iranian community as part of a group called Transportation Options. The group develops educational material and workshops about transportation issues. Presentations were made in Persian schools. Persian community newspapers were also used to raise awareness about transportation issues. Akin to Onziga, Karimi believes that immigrants from Iran may already have instilled in them many of the personal habits that environmental groups raise awareness about. For example, conserving water is a normal practice in Iran as is recycling drinking bottles because Iran has a deposit system for them (Pickering, 1995: 14).

Cecelia Chang, a third new Canadian detailed in Pickering's (1995) article, worked for the federal government as the manager of Asian services for Environment Canada in Vancouver. Chang was responsible for an Environment Canada program established to raise the level of awareness of environmental issues within British Columbia's Chinese community. As part of this initiative, Chang worked with two Chinese radio stations in Vancouver to co-ordinate the broadcast of weather forecasts four times a day in Cantonese and Mandarin. Similar to Onziga's and Karimi's work, Chang also co-ordinated workshops delivered in Chinese about environmental issues and facilitated the translation of environmental information for Vancouver's Chinese community.

Pickering (1995) notes that the environmental endeavours Onziga and Karimi were involved in show the importance of cultural sensitivity when interacting with different ethno-cultural groups on environmental issues. ECENECA has worked with an African music group, recognising that music plays an important role in conveying social messages in various cultures. Karimi, who worked with Iranian women, tried to create an atmosphere of openness and welcomes Iranian men to attend her workshops as well, recognising that in the Iranian culture men may want to accompany their wives to such sessions. The Transportation Options group also worked with 
English as Second Language (ESL) teachers to learn how transportation issues can be introduced into the ESL syllabus, recognising that new arrivals to Canada do spend time learning English.

Pickering (1995) says that Onziga, Karimi and Chang are leaders in the environmental movement, which has long been dominated by middle-class whites. She adds that "they are leaders of initiatives to involve the rich cultural diversity of Canadians in learning about and defining environmental issues" but that barriers to multicultural participation in environmentalism still exist and that environmental groups should recognise the environmental disadvantages faced by people who are poor, unfamiliar with Canadian institutions or uncomfortable in the official languages (Pickering, 1995: 14). Pickering's (1995) article was the only one found that describes the personal efforts of individual immigrants who are taking a proactive approach to environmental issues in an ethno-culturally sensitive way.

\section{Immigrants in the Environmental Movement}

In the Canadian context, Nevitte and Kanji (2003) used data from the 2000 World Values Surveys to analyse immigrant orientations towards sustainability and the environment. The data from this study indicated the following:

1. That as compared to those born in Canada, immigrants have considerably different perspectives towards the environment. As compared to those born in Canada, recent immigrants are less likely to be concerned about the environment and less likely to support environmental protection when costs are involved.

2. Because immigrants are preoccupied with work and other issues of settlement, they are less concerned about the environment. This resonates with the results of the Ethnic Diversity Survey, the 2000 National Survey of Giving Volunteering and Participating, detailed earlier in this chapter.

3. Immigrants' concern for the environment appears unrelated to their willingness to contribute to and become involved in the environmental movement.

In the US context, Pfeffer and Stycos (2002) offer reasons why immigrants may be less likely to participate in environmentally friendly behaviours. The first reason is acculturation. They suggest that differences in American-born and immigrant environmental behaviours stem from 
the fact that immigrants may not yet be socialised in the mainstream US culture. They suggest that as time passes and immigrants become more accustomed to the norms of society differences in environmental behaviour may disappear (Pfeffer and Stycos, 2002: 69). Other reasons for explaining the possibility that immigrants might be less likely to engage environmentally friendly behaviour are community attachment and economic status.

Community attachment is a factor of environmental behaviour that was also discussed in the Ethnic Diversity Survey (EDS), in this chapter. According to Pfeffer and Stycos (2002) the growth in grassroots environmental organisations suggests that people are becoming interested and attached to their local environments and as a result would be more likely to engage in environmental behaviours that enhance and protect these environments.

\section{Discussion and Summary of Key Points}

This chapter detailed various studies that were used to inform the research question. However, these studies are fragmented and do not answer the research question fully. Because of the fragmentation across data sets, comparisons cannot accurately be made. For example, The 2000 NSGVP conveys data at the national and provincial levels whereas Statistics Canada's EDS conveys data by generational grouping and by ethnic group.

Despite this, the two data sets do reveal common themes: (1) that participation of immigrants in Canadian society increased as time in Canada increased; (2) first generation or recent immigrants were more likely to participate with a religious-affiliated group.

The 2000 NSGVP provides an in-depth demographic profile of Canada's volunteers, including new immigrants. It also provides information specific to Ontario's volunteers. However, it does not provide any information about the ethno-cultural makeup of the volunteers surveyed, whereas the EDS does provide ethno-cultural breakdowns as part of its analysis. 
Another difference between two data sets is that the 2000 NSGVP provides information about Canada as a whole and by province whereas the EDS only provides information on a national level, which makes it hard to draw conclusions specific to Toronto, the geographic location of this study.

Also it is clear that the literature surrounding how environmental groups are engaging ethnocultural groups in environmental activities is limited and piecemeal at best. The TRCA produced the Human Connections video and developed a list of responses to barriers that new Canadians might experience but it is unclear whether these responses have been utilised by other environmental groups who have attempted to engage with ethno-cultural groups in Toronto. The motivations different ethno-cultural groups might have to participate in environmental programs also remains unaddressed in the current literature.

Also, the existing research does not reveal how environmental organisations are recruiting ethnocultural participants and whether or not environmental activities are being planned and implemented differently for specific ethno-cultural groups. The interactions between the environmental and ethno-cultural groups are only briefly described by Mitra (2001). She does not provide a full description of the different types of interactions that may be uncovered when the environmental activities are examined more closely. It is also unclear whether the ethnocultural groups involved in these interactions were Canadian-born visible minorities or immigrants.

Reasons such as the preoccupation with meeting basic needs were given to explain why immigrants may not be interested in environmental activities (Nevitte and Kanji 2003). In contrast to this, Gosine (2003) and Taylor (1993) suggest that ethno-cultural groups are interested in environmental issues and they carry an environmental ethic from their homelands but that they do not participate in mainstream environmental activities because the issues are framed in ways that are not relevant to them. 
While previous Toronto-based and Canadian-based publications in the form of directories have attempted to generate interactions between environmental and ethno-cultural groups, because these publications were only produced once, it is difficult to gauge the impact they actually had in establishing contact, communication and interactions between these two groups. Furthermore, because no follow-up studies were conducted after these publications were made, information which speaks to the best practices of how environmental groups can engage ethno-cultural groups is not available specifically for Toronto.

The following chapter outlines the research methods used to conduct this study. 


\section{Chapter III: Methods}

This chapter provides a description of the research methods used in this study. The purpose and rationale, primary and secondary data collection methods, informed consent process, the organisation of the interview protocol and sampling method are discussed.

\section{Purpose and Rationale}

This study brings together three fields of research: environmental management, volunteering and ethno-cultural diversity. The previous two chapters have established that Toronto is an ethnoculturally diverse city and that ethno-cultural groups are involved and participate in the environmental movement in different ways. However, these interactions have not previously been documented or examined in one consolidated source. The information about how various Toronto-based environmental groups are encouraging ethno-cultural groups to participate in environmental activities is at best outdated and fragmented.

The geographic boundary of this study was the City of Toronto located in Ontario, Canada. The purpose of this study was to answer the overall question: How are environmental groups encouraging ethno-cultural groups to participate in environmental activities in Toronto?

In answering the research question, I sought to also answer the following questions:

- What types of interactions occur between environmental and ethno-cultural groups?

- How are these interactions planned and implemented?

- What are the characteristics of the environmental groups involved?

- What are the characteristics of the ethno-cultural groups involved?

- What are the best practices of environmental groups working with ethno-cultural groups? 
A study such as this has never been undertaken in Toronto and is exploratory in nature. Exploratory research has six main functions, as described below:

- To become familiar with the basic facts, setting concerns

- To create a general mental picture of conditions

- To formulate and focus questions for future research

- To generate new ideas, conjectures or hypotheses

- To determine the feasibility of conducting research

- To develop techniques for measuring and locating future data. (Neuman, 2000: 22)

This study will be of interest to environmental groups in Toronto and elsewhere that would like to learn from the experiences of other environmental groups regarding how to encourage and engage ethno-cultural groups to participate in environmental activities.

This study examined the interactions between environmental groups and ethno-cultural groups in Toronto by gathering data directly from the environmental groups, from the perspective of the person within the environmental group who plans and implements volunteer environmental activities. This individual served as the key informant. The rationale for selecting key informants from each environmental group examined was that they were able to provide first-hand information about the activities and interactions that occurred between their environmental group and ethno-cultural groups.

\section{Primary Data Collection Methods}

Primary data refers to data which is gathered first-hand by the researcher. To answer the research question two methods of primary data collection were used. The first method was through a selfadministered questionnaire which the respondent was asked to fill out, but not required. The purpose of the questionnaire was to gather information about the key informant's role within the environmental organisation and to gather a profile of the ethno-cultural groups involved in the selected environmental activities. This type of data was straightforward and gathering this 
information through a self-administered questionnaire would allow for the research interview to focus on aspects of this study that required more in-depth and detailed explanation.

The completion of the questionnaire, however, was left optional because I did not want to lose the participation of key informants who could not devote the time to filling out a questionnaire and participating in an interview. In order not to lose the information sought in the questionnaire, the same questions were asked to the key informants during the interview. Because of this flexibility, key informants generally opted not to fill out the self-administered questionnaire but agreed that instead the same questions could be asked as part of the interview. In cases where key informants did fill out the self-administered questionnaire, I found that the answers they provided were not in full and further clarification was needed. This then became the starting point of the interview. Although the self-administered questionnaire was not filled out fully by the key informants, it served as a way of getting the key informants to think about the interview before hand. In that sense, the self-administered questionnaire acted like a 'cheat sheet' to which key informants referred during the interview.

The second method of primary data collection was a research interview. Research interviewing is a form of qualitative research that is grounded in the structure of a conversation, allowing "the researcher to adjust the pace and style of asking questions so as to bring out the best in the respondents" (Hannabuss, 1996: 22). Qualitative research places importance "on seeing the world from the viewpoint of the 'actor'", which in this study was the program co-ordinator of each environmental program examined. The gender split and specific job titles of key informants appears later in this chapter.

The purposes of a research interview are outlined by Hannabuss (1996): "We want the respondents' own perspective to emerge, explore the way in which people working together share common understandings, get insight into particular experiences, find out motives behind decisions, get a view of informal procedures, consider apparent contradictions between attitudes and behaviour, and allow respondents time to provide their answers" (23). 
Research interviews are advantageous in that they are a good way to extract opinions about complicated and sensitive issues and they can be adapted by the interviewee to the suit the respondents' "level and personality... and draw out the spontaneous reactions of the respondents" (Hannabuss, 1996: 23). In contrast, research interviews are time consuming. Tape recording the interviews may also pose a problem according to Hannabuss (1996) because the key informants "may not want to talk 'on the record', may respond in idiosyncratic ways which makes comparison with other respondents difficult and may say so much that organizing the information afterwards is time-consuming and complicated" (24). However, an advantage of tape recording interviews is that the recording can be played back to extract direct quotes and the emotion and context in which the phrase was said can easily be sensed.

The research interview was semi-structured in that the researcher used an interview guide with a consistent set of questions asked to each interviewee but the researcher was allowed to probe for further information based on the information received during the interview (Blee and Taylor, 2002: 92). Interviews with key informants focused on a specific environmental program which had been identified by the researcher prior to the interview.

Nine of the ten key informants agreed to the recording of their interviews. Hand-written notes were made to record information during the unrecorded interview. Tape-recording the interviews meant that focus could be kept on the interview discussion and not on note-taking while the key informant was responding to questions.

\section{Informed Consent Process}

To minimise the likelihood of key informants not wanting to talk 'on the record', an informed consent process was used. Each key informant was asked to sign a consent form indicating that they agreed to participate in this study. As part of this consent form, key informants were also guaranteed that their names would not appear anywhere in this study. Key informants were asked to indicate on the consent form whether or not they give permission for their interview to be tape-recorded. Key informants were also made aware that the tape recording of their interview 
would be held in a secure cabinet to which only I would have access and that after six months the tapes would be destroyed.

\section{Organisation of Interview Protocol}

The interview protocol was divided into three sections. Section A presented general questions about the environmental organisation the key informant was involved with. Section B presented questions about environmental activities carried out by the organisation that the key informant was involved with. Section B also asked about the ethno-cultural breakdown of volunteers. Sections A and B were formatted as a self-administered questionnaire, which the interviewee could respond to in writing, prior to the interview, if they wished, as explained above.

Section $\mathrm{C}$ presented detailed questions that were better suited for discussion during the interview. These questions were provided to the key informant prior to the interview so that they could prepare for the interview if needed.

Section $\mathrm{C}$ was divided into four sections. The first section included questions about the environmental organisation and the environmental activities the key informant was involved with, expanding on the questions asked in sections $\mathrm{A}$ and $\mathrm{B}$. The second section included questions about why and how ethno-cultural groups became involved in the environmental program. The third section included questions about how ethno-cultural groups were recruited and how the environmental activity was funded. The fourth section involved questions about aspects of the environmental activity that were changed by the environmental group to facilitate working with ethno-cultural groups more easily. These categories of questions were selected because they relate back to the research question and the sub-questions previously noted. The interview protocol can be reviewed in Appendix B.

The interview protocol was structured so that the more straight forward questions were at the beginning of the interview and the more challenging ones were placed at the end. The reason for using this structure was that by starting the interview with simpler questions, both the 
interviewer and the key informant are given the chance to warm up and get comfortable in the interview setting before addressing questions which required in-depth probing, discussion and explanation.

\section{Setting up the Interview}

Prior to the interview date, I had already spoken with each key informant. This was done by an initial telephone call to key informants, during which I informed them about this study and that if they agreed, an information letter would be sent to them, which would provide further details about the research.

Another telephone call was made to the key informant after the information letter was mailed to them. The purpose of this follow-up call was to confirm that the information letter had been received, to answer any questions they had and to ask if they would be able participate in the study. Once the key informant agreed to participate in the study, the interview protocol and the consent form were mailed or emailed to them. A third telephone call was made to the key informant after this to confirm that these pieces of information were received in good order and to book an interview date.

Interviews for this study were conducted between April and May 2005. Interviews were held in most cases at the workplace of the key informant, usually in the boardroom or an area where a discussion could be had without disruptions. In one case an interview was conducted at a public library, simply because the group did not have a dedicated meeting place.

\section{Secondary Data Collection Methods}

Secondary data refers to data that already exists, which is not gathered first-hand by the researcher. Secondary data relevant to this study such as previous studies, journal articles, books and survey results were reviewed and detailed in Chapters 1 and 2. Online academic search portals such as Ingenta, Proquest Research Library and Elsevier Journals were accessed. All of 
these scholar portals are searchable with similar search categories which include key words, author's name, date of publication, journal title and article title.

One limitation of searching online scholar portals is that in some cases only abstracts of studies or articles are available, which means that the original print source must be accessed to obtain the full text of the document. A second limitation of online scholar portals is that they only yield issues of journals which have been digitised and inputted into the database. In most cases this meant that articles that were published before the 1990s would likely not be available in online portable formats. Because of this, a manual library search for literature was also undertaken which yielded articles relevant to this study which were not searchable or available online.

While secondary data was used primarily for the literature reviews presented in the first two chapters, secondary data was also accessed during the process of environmental program selection for this study. Specifically the Internet was used to gather information about those organisations that had a Website. The Internet also acted as a point of reference for general information about the selected organisations. Information such as their contact information, major projects, accomplishments, online publications were accessible via the Internet. This process enabled in some cases the confirmation that selected projects had been completed or that they were still active and on-going. Reviewing the groups' websites also facilitated easy access to information about funding and other partners, which are often mentioned along with their logos. The websites were also useful in obtaining the current contact information of potential key informants.

\section{Sampling Method}

The sampling method used for this study is called purposive or judgemental. When using purposive sampling "the researcher never knows whether the cases selected represent the population. It is used in exploratory research" (Neuman, 2000: 198). Purposive sampling can be used in three circumstances, as described below: 
1. Purposive sampling can be used to select cases that are particularly informative.

2. Purposive sampling can be used to identify difficult-to-reach or specialised populations. In this instance the researcher can use many different methods to pinpoint the cases because the goal at this point of the research is to identify as many cases as possible.

3. Purposive sampling can be used to isolate particular types of cases for in-depth exploration. The purpose of this does not have to do with uncovering generalisations that can be made to the larger population. Rather, the purpose is to acquire an in-depth understanding of the case types.

(Neuman, 2000: 198).

Specifically, purposive sampling in this study was used to select cases that would be particularly informative and to identify specialised populations - that is environmental groups in Toronto that have encouraged ethno-cultural groups to participate in their environmental activities.

\section{Sample Selection}

In Ontario there are hundreds of environmental organisations, representing many different environmental problems, issues and stakeholders. Extensive listings of Ontario's environmental organisations can be found in directories which are available in print or on-line by accessing the Internet. The Ontario Environmental Network's (OEN) Ontario Environmental Directory, available online, is a searchable directory of environmental groups, agencies and websites, which is publicly available. An interesting feature of this online directory is that it has a search feature which allows one to search for environmental organisations by name, location, keyword or area of interest. Searchable themes include education, toxics, air, water, waste and energy, to name a few. For each listed organisation, information such as a contact telephone number, location, a brief description of the organisation's main activities and a website address (if available) are provided.

The print version of the Ontario Environmental Directory is called the Environmental Resource Book. Of its 889 listed organisations, the Ontario Environmental Directory lists 288 environmental organisations for Toronto. The Green List, available in print and CD formats is another resource, in which Canadian Environmental organisations and agencies are listed, in a 
similar fashion to the Ontario Environmental Directory. The City of Toronto website also has an online directory of environmental groups, which is publicly accessible and which can be viewed at www.toronto.ca/greentoronto/greengroups.htm. There are 25 green groups listed at this webpage and groups are listed by different categories - by watershed or geographic area, nonwatershed, Toronto waterfront related and in alphabetical order.

These green groups are listed as part of the City of Toronto's Stewardship Website. The purpose of the Stewardship Website is to "act as a clearing-house, providing information on all aspects of stewardship in the City of Toronto. Whether you are an individual looking to get involved or a stewardship group hoping to network with other groups in your community, the Stewardship Website will set you off in the right direction" (Welcome, 2005).

While these directories are a good starting point to find out basic information about environmental groups in Toronto, they do not provide any indication of which groups have been encouraging ethno-cultural groups to participate in environmental programming. This is because these directories do not provide in-depth descriptions of all environmental activities planned and implemented by each group. Also, the Ontario Environmental Directory and the Green List include too many environmental groups representing a myriad of interests. Examining each group to determine which ones were interacting with ethno-cultural groups would have exceeded the timeframe of this study.

Because of these limitations, alternative sources were accessed to yield a more focused and smaller sample of environmental groups which could be examined within the timeframe of this study. The first resource which was useful in obtaining a specific pool of environmental groups whose activities have involved non-white ethno-cultural groups was the 2000 People of Colour Environmental Groups directory compiled by Environmental Justice Resource Centre which incorporates listings for the US, Mexico and Canada. The Canadian listings were categorised by province. For Ontario, 22 groups were listed, of which twelve are located within the City of Toronto. For each listed organisation, the information provided includes the address, a contact name, a brief description of issues the organisation deals with, the number of paid staff and 
volunteers, constituency (ethno-cultural) group served, geographic focus, membership base and year the organisation was founded. Because this directory was five years old and subsequent directories were not produced which could indicate whether or not the Toronto-based environmental groups were still operating, other sources were also examined.

A second resource which was useful in obtaining a narrower pool of environmental groups whose activities involved ethno-cultural groups was Sustainability Network's 2001 Directory of Ethno-cultural Organizations and the Environment. The Directory yielded six environmental groups but because this source was four years old and no subsequent directories were produced by Sustainability Network, other more current sources were sought again.

As an outcome of Sustainability Network's directory, a forum was held in which guest speakers were asked to present their insights and experiences with working with ethno-cultural groups on environmental activities. In most cases the guest speakers were from the six environmental groups identified in the directory as having worked with ethno-cultural groups.

In September 2004 the first ever Environmental Fair for Newcomers to Canada was held. This fair was organised by the Toronto and Region Conservation Authority as a way to encourage new Canadians to seek volunteer and employment opportunities in the environmental sector. Because the Environmental Fair was held seven months before interviews for this study began, it was considered to be a current and accurate source of information on groups that were encouraging ethno-cultural groups to participate in their environmental activities or at the very least acknowledging that ethno-cultural groups were present in Toronto and should be included in their environmental activities.

My attendance at the Fair was also useful because I could collect an up-to-date sample of environmental groups that were in most cases Toronto-based. It was however still unclear from merely attending the fair which environmental groups were actually encouraging ethno-cultural groups to participate in their environmental activities. To assist in discerning this more clearly, I had brief discussions with the representatives of each environmental organisation present. During 
these discussions, the purpose of this research was explained to the representatives and the representatives responded by either indicating that some of their organisation's environmental activities would fall within the realm of this study whereas others responded that the activities of their organisation were beyond the scope of this study. When a representative indicated that its organisation's activities fell within the realm of this study, a review of its website was undertaken as well as a review of any of its printed materials that were available at the Fair.

The Green Ontario website was also used as a source in determining a tighter pool of environmental organisations and projects that would fall within the range of this study. The Green Ontario website is a project of the Conservation Council of Ontario (CCO), which is a non-governmental, charitable organisation whose mandate is "to promote cooperation for conservation and a healthy environment in Ontario, Canada" (Who We Are, 2002). The CCO's membership includes both provincial groups and individuals who support the CCO's mandate and who are dedicated to taking province-wide and co-operative approaches in solving environmental problems.

Under the Factsheet heading of the Green Ontario website, there is a link to a page called Multiculturalism and Environment. This page was useful because it specifically lists environmental groups that have worked with ethno-cultural groups.

The environmental groups selected for this study fit the following criteria:

1. The environmental group is based in Toronto

2. The environmental group organises and implements environmental activities

3. These environmental activities are voluntary in nature

4. These environmental activities are carried out in Toronto

5. The environmental group participated in an Environmental Job Fair for Newcomer Canadians, held in September 2004 and / or 
6. The environmental group had been listed as being engaged in ethno-cultural and environmental activities in the 2001 Ontario Directory: Ethno-cultural Organizations and The Environment and / or

7. The environmental organisation was highlighted at Sustainability Network's Diversity Forum held in 2001 and / or

8. The environmental group was listed in the 2000 Directory People of Color and Environmental Groups and / or

9. The Environmental group was mentioned on the Green Ontario Provincial Strategy website.

Criteria 1 to 4 were relevant to the geographic location of the environmental group and the group's environmental activities. Each environmental group selected for this study fulfilled selection criteria 1 to 4 . Selection criteria 5-9 functioned in a different way - environmental groups selected for this study were associated with at least one of the environmental and ethnocultural events or publications mentioned therein.

Selection criteria 5-9 were derived from different sources ( 2 directories, a forum, a website and an environmental fair) and from different years (2000, 2001 and 2004). The newest source of information came from the Environmental Fair for Newcomers to Canada, held in September 2004. It is unclear when the Green Ontario website was established and last updated.

It may be the case that environmental groups that existed prior to 2000, which were not captured in the People of Colour Environmental Groups may have been dismantled and therefore are not referenced in this study. Conversely, it may be the case that the environmental groups existed at the time of publication of these documents and at the time of the forum but perhaps they were not interacting with ethno-cultural groups at that time.

Some cases arose where the projects of the environmental groups listed in the 2000 and 2001 sources were no longer operating at the time of the 2004 Environmental Job Fair and / or at the time this study began. In these cases, the environmental group and its corresponding project were 
still included in the study because there was a potential key informant available who could speak about the completed project.

The Figure 13 indicates the source or sources of each environmental group initially selected for this study:

Figure 13: Sources of Environmental Groups Initially Selected

\begin{tabular}{|c|c|c|c|c|}
\hline $\begin{array}{c}\text { Environmental Group } \\
\text { Name }\end{array}$ & $\begin{array}{c}\text { Environmental } \\
\text { Fair for New } \\
\text { Comers }\end{array}$ & $\begin{array}{c}2001 \\
\text { Ontario } \\
\text { Directory }\end{array}$ & $\begin{array}{c}2000 \\
\text { Directory: } \\
\text { People of } \\
\text { Color }\end{array}$ & $\begin{array}{c}\text { Green } \\
\text { Ontario } \\
\text { Website }\end{array}$ \\
\hline $\begin{array}{c}\text { Black Creek Conservation } \\
\text { Group }\end{array}$ & * & & & \\
\hline Earth Day Canada & $*$ & & & \\
\hline EnerACT & * & & & \\
\hline $\begin{array}{c}\text { Environmental Centre for } \\
\text { New Canadians (ECENECA) }\end{array}$ & & & * & $*$ \\
\hline Evergreen & * & & & * \\
\hline Future-Watch & & * & & \\
\hline Greenest City & & & & $*$ \\
\hline $\begin{array}{l}\text { Multiracial Network for } \\
\text { Environmental Justice } \\
\text { (MNEJ) }\end{array}$ & & * & & $*$ \\
\hline $\begin{array}{c}\text { Scadding Court Community } \\
\text { Centre }\end{array}$ & & * & & \\
\hline $\begin{array}{c}\text { The Stop Community Food } \\
\text { Centre }\end{array}$ & $*$ & & & \\
\hline $\begin{array}{c}\text { Toronto \& Region } \\
\text { Conservation Authority }\end{array}$ & * & * & & * \\
\hline $\begin{array}{c}\text { Toronto Chinese Health } \\
\text { Education Committee } \\
\text { (TCHEC) }\end{array}$ & & $*$ & $*$ & * \\
\hline $\begin{array}{c}\text { Toronto Environmental } \\
\text { Volunteers }\end{array}$ & * & & & \\
\hline
\end{tabular}

In total 13 environmental groups were identified representing 16 projects in which ethno-cultural groups were involved in varying capacities. The following table lists the environmental groups and their corresponding projects, which were targeted for this study. Of the 13 environmental 53 
groups targeted, 10 participated in this study. A synopsis of each environmental group is provided in the following chapter.

Figure 14 shows the environmental groups that participated in this study. Of those that were initially selected, three environmental groups did not participate in this study. Two of these three environmental groups did not respond to the initial telephone call. A second telephone call was made which also received no response. The third environmental groups could not be contacted because its telephone number was not in service. This environmental group did not have a website where current contact information and the status of the group could be assessed.

Figure 14: Participating Environmental Groups

\begin{tabular}{|c|c|}
\hline $\begin{array}{c}\text { Environmental Group } \\
\text { Name }\end{array}$ & Participated in Study \\
\hline $\begin{array}{c}\text { Black Creek Conservation } \\
\text { Group }\end{array}$ & No \\
\hline Earth Day Canada & Yes \\
\hline EnerACT & Yes \\
\hline $\begin{array}{c}\text { Environmental Centre for } \\
\text { New Canadians (ECENECA) }\end{array}$ & Yes \\
\hline Evergreen & Yes \\
\hline Future-Watch & Yes \\
\hline Greenest City & No \\
\hline $\begin{array}{c}\text { Multiracial Network for } \\
\text { Environmental Justice } \\
\text { (MNEJ) }\end{array}$ & No \\
\hline $\begin{array}{c}\text { Scadding Court Community } \\
\text { Centre }\end{array}$ & Yes \\
\hline $\begin{array}{c}\text { The Stop Community Food } \\
\text { Centre }\end{array}$ & Yes \\
\hline $\begin{array}{c}\text { Toronto \& Region } \\
\text { Conservation Authority }\end{array}$ & Yes \\
\hline $\begin{array}{c}\text { Toronto Chinese Health } \\
\text { Education Committee } \\
\text { (TCHEC) }\end{array}$ & Yes \\
\hline $\begin{array}{c}\text { Toronto Environmental } \\
\text { Volunteers }\end{array}$ & \\
\hline
\end{tabular}


Figure 15 provides a synopsis of the environmental groups included in this study. Information such as the year the group was established, its total number of employees and the total number of employees dedicated to the environmental program are detailed. This information is given to provide a sense of the dimensionality and prominence of the groups included in this study.

Figure 15: Summary of Participating Environmental Groups

\begin{tabular}{|l|c|c|c|c|}
\hline $\begin{array}{c}\text { Environmental } \\
\text { Group }\end{array}$ & $\begin{array}{c}\text { Year } \\
\text { Established }\end{array}$ & $\begin{array}{c}\text { Years } \\
\text { operating }\end{array}$ & $\begin{array}{c}\text { Total Number of } \\
\text { Employees in } \\
\text { Environmental Group } \\
\text { (in Toronto) }\end{array}$ & $\begin{array}{c}\text { Number of } \\
\text { Employees Dedicated } \\
\text { to Environmental } \\
\text { Program Examined }\end{array}$ \\
\hline Earth Day Canada & 1990 & 15 & 11 & 2 \\
\hline ECENECA & 1993 & 12 & 1 & 1 \\
\hline Eneract & 1989 & 16 & 5 & 1 \\
\hline Evergreen & 1991 & 14 & 33 & 1 \\
\hline Future Watch & 1993 & 12 & 4 & 1 \\
\hline $\begin{array}{l}\text { Scadding Court } \\
\text { Community } \\
\text { Centre }\end{array}$ & 1978 & 27 & 20 & 1 \\
\hline $\begin{array}{l}\text { TCHEC } \\
\text { The Stop } \\
\text { Community Food } \\
\text { Centre }\end{array}$ & early 1970s & $30+$ years & 12 & only volunteers \\
\hline $\begin{array}{l}\text { Toronto } \\
\text { Environmental } \\
\text { Volunteers }\end{array}$ & 1996 & 9 & only volunteers & 1 \\
\hline TRCA & 1946 & 49 & over 600 & 1 \\
\hline
\end{tabular}

Eight of the ten groups included in this study are Non-Governmental Organisations (NGOs). The TRCA and the Toronto Environmental Volunteers cannot be classified as NGOs. The TRCA is an environmental group which functions under the province of Ontario's Conservation Authorities Act. In contrast, Toronto Environmental Volunteers is an environmental group formed by the City of Toronto. While these two groups are not NGOs, they were retained in the study sample because this study focused on the environmental programs that environmental groups were implementing regardless of funding sources or organisation type. 


\section{Key Informants}

Ten key informants participated in this study. Three key informants were male and seven were female. Key informants had different job titles which described the positions they held within the environmental group they represented. Below is a list of the job titles of the ten key informants:

- Community Environmental Outreach Technician

- Project Co-ordinator

- Volunteer Co-ordinator

- Program Co-ordinator

- Manager

- Chairperson

- Community Development Worker and Urban Agriculture Co-ordinator

- Executive Director and Co-ordinator

- Community Gardens Co-ordinator

- Urban Agriculture Co-ordinator

\section{Data Analysis}

The recordings of the key informant interviews formed the raw data gathered and analysed for this study. According to Neuman (2000) qualitative data is analysed by organising it into categories on the basis of themes, concepts or similar features and the relationships among concepts are explored.

Once all of the data was gathered for this study, qualitative coding began. "Qualitative coding is an integral part of data analysis. It is guided by the research question and leads to new questions" (Neuman, 2000: 420). Coding involves two simultaneous tasks - mechanical data reduction and analytic categorisation of data into themes.

Three types of qualitative data coding were used in this study - open coding, axial coding and selective coding. Open coding was performed during the first pass through of the data. Open coding allowed for the large amount of data collected to be condensed into more manageable categories. Axial coding occurs during the second pass through the data. During this phase of data review, the themes identified during open coding are examined, with attention to identifying causes, consequences, conditions, interactions, strategies and processes (Neuman, 2000). 
Selective coding is the last pass through the data which involves looking for examples that illustrate themes and making comparisons and contrasts.

Nine of the ten key informants agreed to have their interview tape recorded. For these nine interviews, the tape recorded interviews were listened to and qualitatively coded in this way. In the case where the key informant did not agree to tape recording the interview, hand written notes were made and also reviewed three times as described above.

\section{Discussion and Summary of Key Points}

This was a qualitative, exploratory study which has not previously been undertaken in Toronto. Through purposive sampling, thirteen environmental organisations were initially identified for this study through two environmental directories, an environmental fair for newcomers to Canada and the Green Ontario website. Ten of the potential thirteen environmental organisations participated in this study.

Primary data was collected through semi-structured interviews with key informants from various environmental organisations in Toronto. A key informant was the person most closely associated with the environmental program under examination. Three key informants were male and seven were female. Key informants were required to sign a consent form indicating that they agreed to have their interview tape recorded. The data gathered during the interviews was analysed using open, axial and selective coding to reveal concepts of causes, consequences, conditions, interactions, strategies and processes. These themes are discussed and explored in the following two chapters - Findings and Analysis. 
$\bullet$ 


\section{Chapter IV: Findings}

In this chapter the findings of this study are presented. In the following chapter the significance of these findings as they relate to the research questions and the literature review is presented. Before the findings are discussed however, a synopsis of each environmental program included in this study is detailed below.

\section{Synopsis of Environmental Programs Examined}

As part of the informed consent process key informants were guaranteed that their answers to the interview questions would not be directly referenced back or traceable to them or their environmental program. Figure 16 provides basic information about each program without using the official program name or referencing the specific environmental group which runs the program. Each program described below has been assigned an alphanumeric code beginning with the letter $\mathrm{P}$ followed by a number ranging from one to ten. In one case, an environmental group had three programs which are differentiated by a lowercase letter following the alphanumeric identifier (P6a, P6b and P6c). In addition to Figure 16, the following paragraphs provide some detail about the programs and the respective environmental organisations.

P1:

This program is an urban agriculture program which is run by a non-governmental community food centre in the southwest part of the City of Toronto. Originally established as a food bank, this environmental group has expanded its programs and services to include a community bake oven, support for families with newborns and prenatal nutrition classes. This urban agriculture program has been operating since 1998 .

P2:

Created by and geared to members of the Chinese community in Toronto. This program was established in 1993 and has since trained approximately 60 members of the Chinese community on environmental issues such as global climate change, energy conservation, pesticide use and 
more recently, the One-Tonne Challenge ${ }^{1}$. The environmental group that runs this program is a non-registered, non-governmental group and the smallest group to participate in this study.

\section{P3:}

This program is a City of Toronto initiative in which volunteers must complete 20 hours of environmental training followed by 40 hours of environmental outreach such as participating in the City of Toronto's Environment Days, running workshops about environmental issues or volunteering with other environmental organisations. Environmental training includes learning about solid waste management, garbage, recycling, composting, energy efficiency and water efficiency.

P4:

This urban agriculture program is run by a multi-service, non-governmental community centre serving the downtown west area of the City of Toronto. The urban agriculture program has been operating since 1998. This urban agriculture program involved provision of community garden plots which are organic, pesticide free and herbicide free. Other services offered by this community centre included free access to computers, computer classes, English classes for new Canadians and a community kitchen.

P5:

This program focused on creating environmental experiences for new Canadians. Examples of these environmental experiences include visits to a maple sugar bush and other recreational areas for new Canadians who have received their citizenship. These events were planned in conjunction with the official Canadian citizenship ceremony. This program was run by the largest environmental group included in this study. This program also had other projects such as taking ESL classes on a one-hour guided tour of a maple sugar bush or conservation area.

\footnotetext{
The One-Tonne Challenge is a National Campaign aimed at educating Canadians about ways to reduce their energy consumption and greenhouse gas emissions.
} 
P6a:

This and the following two programs (P6b and P6c) were run by the same environmental group, located in the southwest part of the City of Toronto. This group focuses on community capacity building through environmental education. This program involved naturalisation, gardening and planting activities with the Spanish and Somali communities.

P6b:

This program also involved the Spanish and Somali communities. The intent of this program was to educate these communities about climate change by creating local solutions which could be used to save energy, reduce energy costs and reduce pollution. Workshops were held with each ethno-cultural group to teach them ten simple actions they could take to be more environmentally friendly in their daily lives.

P6c:

This program is a spin off of P6b. It focuses on the One-Tonne Challenge and was also being geared particularly to the Spanish and Somali communities. During the time of the data collection this program had just begun recruiting potential workshop facilitators - one from the Spanish community and one from the Somali community. Once these facilitators were trained they would run workshops geared to their specific ethno-cultural group.

P7:

This program began its pilot phase in early 2005 by specifically targeting the Chinese community. The goal of this program was to raise awareness through workshops and interactive sessions about energy conservation and how homeowners and tenants can be energy efficient. Now in its first phase implementation phase, this program is being expanded to the South Asian and West Indian communities in Toronto. The second phase of implementation will include the Italian, Portuguese and Filipino communities. This program is run by a non-governmental, environmental group based in Toronto. 


\section{P8:}

This program, run by a national, non-governmental environmental group, involved urban gardens at three different downtown locations in the City of Toronto. These community gardens were established in 1998 and the program ran formally for three years. These gardens were sited in areas that were ethno-culturally diverse. Today these gardens are self sufficient and require minimal upkeep because native species were planted.

P9:

This program aims to improve the quality of the environment by assisting Canadians to be proactive at the household level. This program is primarily Internet based and its intent is to teach Canadians simple actions which could be taken in daily life at any time of year to conserve energy and become more resource efficient. This program is run by a national, environmental communications group based in Toronto.

P10:

The aim of this program was to expose new Canadians to environmental issues through tree planting. This program began in 1999 and lasted for only one planting season. The program was not re-established the following year. This program was run by one of the smallest environmental groups included in this study. 
Figure 16: Summary of Environmental Programs Examined

\begin{tabular}{|c|c|c|c|c|c|}
\hline \multirow{2}{*}{$\begin{array}{l}\text { Program } \\
\text { Code }\end{array}$} & \multirow{2}{*}{ Primary Activities } & \multicolumn{3}{|c|}{ Program } & \multirow[b]{2}{*}{ Participating Ethno-cultural Groups } \\
\hline & & $\begin{array}{l}\text { Start } \\
\text { Date }\end{array}$ & $\begin{array}{l}\text { End } \\
\text { Date }\end{array}$ & Status & \\
\hline $\mathrm{P} 1$ & $\begin{array}{l}\text { Community gardening, } \\
\text { community bake oven, }\end{array}$ & 1998 & - & $\begin{array}{l}\text { Currently } \\
\text { operating }\end{array}$ & $\begin{array}{l}\text { Italians, Portuguese, Turkish, Jamiacans, } \\
\text { Africans, Chinese, Arabs, Latin Americans. } \\
\text { Specifically targeted and garden is located in } \\
\text { area where these ethno-cultural groups live. }\end{array}$ \\
\hline $\mathbf{P} 2$ & $\begin{array}{l}\text { Education \& awareness } \\
\text { about envionmental } \\
\text { issues }\end{array}$ & 1993 & - & $\begin{array}{l}\text { Currently } \\
\text { operating }\end{array}$ & Chinese / Mandarin - Specifically targeted \\
\hline P3 & $\begin{array}{l}\text { Education about solid } \\
\text { waste management, } \\
\text { garbage, recycling, water } \\
\text { efficiency, energy } \\
\text { efficiency, air quality, } \\
\text { composting }\end{array}$ & 1997 & - & $\begin{array}{l}\text { Currently } \\
\text { operating }\end{array}$ & * \\
\hline P4 & $\begin{array}{l}\text { Community gardening } \\
\text { plots, community } \\
\text { kitchen, composting, } \\
\text { greenhouse gases }\end{array}$ & 1998 & - & $\begin{array}{l}\text { Currently } \\
\text { operating }\end{array}$ & $\begin{array}{l}\text { Chinese seniors, South East Asians, Africans, } \\
\text { Portuguese and Tamils. Not specifically } \\
\text { targeted but garden located in area where } \\
\text { these ethno-cultural groups live. }\end{array}$ \\
\hline P5 & $\begin{array}{l}\text { Creating environmental } \\
\text { experiences for new } \\
\text { Canadians }\end{array}$ & 2005 & - & $\begin{array}{l}\text { Currently } \\
\text { operating }\end{array}$ & $\begin{array}{l}\text { New Canadians - ethno-cultural groups not } \\
\text { specifically targeted }\end{array}$ \\
\hline P6a & $\begin{array}{l}\text { Naturalisation, Planting, } \\
\text { Gardening }\end{array}$ & 2002 & 2003 & Completed & $\begin{array}{l}\text { Spanish and Somali community residing in } \\
\text { vicinity specifically targeted }\end{array}$ \\
\hline P6b & $\begin{array}{l}\text { Climate Change } \\
\text { Awareness }\end{array}$ & 2004 & 2004 & Completed & $\begin{array}{l}\text { Spanish and Somali community residing in } \\
\text { vicinity specifically targeted }\end{array}$ \\
\hline P6c & $\begin{array}{l}\text { Raising awareness about } \\
\text { the One Tonne } \\
\text { Challenge }\end{array}$ & 2005 & - & $\begin{array}{l}\text { Currently } \\
\text { operating }\end{array}$ & $\begin{array}{l}\text { Spanish and Somali community residing in } \\
\text { vicinity specifically targeted }\end{array}$ \\
\hline P7 & $\begin{array}{l}\text { Energy conservation } \\
\text { education }\end{array}$ & 2005 & - & $\begin{array}{l}\text { Currently } \\
\text { operating }\end{array}$ & $\begin{array}{l}\text { Specifically targeted Chinese community in } \\
\text { Pilot Phase. Now focusing on South Asian } \\
\text { and West Indian commnity. }\end{array}$ \\
\hline P8 & $\begin{array}{l}\text { Gardening / planting, } \\
\text { cleaning up garbage, } \\
\text { learning about native } \\
\text { species }\end{array}$ & 1998 & 2000 & $\begin{array}{c}\text { Gardens self } \\
\text { sufficient - no } \\
\quad \text { formal } \\
\text { programming }\end{array}$ & $\begin{array}{l}\text { Indo/Pakistanis, Latin Americans, Africans, } \\
\text { Asians. Not specifically targeted but gardens } \\
\text { located in areas where these ethno-cultural } \\
\text { groups live. }\end{array}$ \\
\hline P9 & Tree planting & 1999 & 1999 & Completed & $\begin{array}{l}\text { New Canadians from Africa, Bangladesh and } \\
\text { Latin America - specifically targeted }\end{array}$ \\
\hline P10 & Conservation of energy & 2002 & - & $\begin{array}{l}\text { Currently } \\
\text { operating }\end{array}$ & * \\
\hline
\end{tabular}

* Indicates that key informant was not able to comment on ethno-cultural groups. 
From the information provided in Figure 16 it is evident that a wide range of environmental activities are included in this study which may raise concerns as to whether or not some of the groups included in the study sample consider themselves as environmental groups. All groups included in this study are environmental groups based on two main reasons. First, the definition of the environmental movement provided in Chapter 1 states that the environmental movement is a new social movement made up of many different causes and issues. For example, those programs included in this study that focus on urban agriculture or community gardening, I would argue are indeed environmental groups because the larger environmental issues being address through these programs relates directly to social and environmental issues such as the provision of safe, healthy food and food security. Second, the programs included in this study were discovered through environmental channels such as environmental fairs or within environmental directories. The fact that these groups are voluntarily associating themselves with environmental channels also serves as an indication that these groups do consider themselves as environmental groups.

Having provided background information about the environmental programs included in this study, the following paragraphs outline the major findings of this study. These findings inform the main research question - How are environmental groups encouraging ethno-cultural groups to participate in environmental activities in Toronto - as well as the sub-questions relating to the types of interactions that occur between environmental and ethno-cultural groups and the way these interactions are planned and implemented. These findings and their implications will be elaborated upon in Chapter 5: Analysis.

In referring to key informants' statements or direct quotes, the same system of alphanumeric identifiers is used, the only difference being that the identifier beings with the letter I followed by the number that corresponds to the numbers in the Figure 16. For example, the key informant for P8 is referenced as I8. Similarly, the key informant for P10 is referenced as I10. This system is used in this and the following chapter. 


\section{Volunteer and Participant Can Have Different Meanings}

During the literature review phase of this study, no research was found that made a distinction between volunteers and participants of stewardship or other environmental activities. Volunteers were written about as the participants of the stewardship group because they were giving their time, energy and effort for the cause of the group without monetary compensation. However, during some of the interviews it became clear that key informants were unsure what was meant by the term volunteer because upon explaining the research to them, it was evident that the research was about individuals who partake in their projects, often referred to as the participants. The way key informants distinguished between volunteers and participants is summarised in Figure 17. 


\section{Figure 17: Distinguishing Between Volunteers and Participants}

\begin{tabular}{|c|c|c|c|c|}
\hline $\begin{array}{c}\text { Key } \\
\text { Informant }\end{array}$ & \begin{tabular}{|c|} 
Distinguished \\
Between \\
Volunteer \& \\
Participant \\
\end{tabular} & Definition of Voiunteer & Definition of Participaut & Quote / Paraphrase (if applicable) \\
\hline II & Yes & $\begin{array}{c}\text { Volunteers are people who work on } \\
\text { a project in any capacity. }\end{array}$ & $\begin{array}{l}\text { Participants are those people who } \\
\text { access the services offered by the } \\
\text { environmental group. }\end{array}$ & $\begin{array}{l}\text { "I consider everyone that works for the } \\
\text { project a volunteer because mostly they } \\
\text { are putting out time...I would consider } \\
\text { participants people who come to the } \\
\text { food bank, who are getting the stuff". }\end{array}$ \\
\hline I2 & No & $\begin{array}{l}\text { Volunteers are those people who are } \\
\text { part of the environmental group. }\end{array}$ & $\cdot$ & - \\
\hline I3 & No & $\begin{array}{l}\text { The participants of the } \\
\text { environmental program are the } \\
\text { volunteers }\end{array}$ & - & - \\
\hline 14 & No & $\begin{array}{l}\text { The participants of the } \\
\text { environmental program are the } \\
\text { volunteers }\end{array}$ & - & - \\
\hline I5 & Yes & $\begin{array}{l}\text { Volunteers are people who provide a } \\
\text { service or skill to the environmental } \\
\text { group. Volunteers benefit the } \\
\text { environmental group. Volunteer } \\
\text { opportunities were those most } \\
\text { suitable for new Canadians who are } \\
\text { looking for career advancement or } \\
\text { development. }\end{array}$ & $\begin{array}{l}\text { Participants are people who do not } \\
\text { benefit the environmental group. } \\
\text { They simply partake in the } \\
\text { environmental programming offered } \\
\text { by the environmental group. }\end{array}$ & $\begin{array}{c}\text { "when I think of participants of our } \\
\text { programs, we are not benefiting per se } \\
\text { but we are providing a service... but a } \\
\text { volunteer would do data base services } \\
\text { for us...for me, a participant in the } \\
\text { program [means] they are signing up } \\
\text { and we 're benefiting them and in the } \\
\text { volunteer sense they're more benefiting } \\
\text { us". }\end{array}$ \\
\hline I6 & Yes & $\begin{array}{l}\text { Volunteers are people who are } \\
\text { building their skills for Canadian } \\
\text { experience. }\end{array}$ & $\begin{array}{l}\text { Participants are people in } \\
\text { programming offered by the } \\
\text { environmental group. }\end{array}$ & $\begin{array}{l}\text { "Volunteers are building their skills in } \\
\text { a Canadian field. Participants want to } \\
\text { know more, to participate". }\end{array}$ \\
\hline 17 & Yes & $\begin{array}{l}\text { Volunteers are those who do the } \\
\text { preparatory work for the } \\
\text { environmental program. }\end{array}$ & $\begin{array}{c}\text { Participants are people who attend } \\
\text { the environmental program / } \\
\text { workshops. }\end{array}$ & $\begin{array}{l}\text { Volunteers do all the "behind the scenes" } \\
\text { tasks like flyer posting and delivery, } \\
\text { door to door canvassing about the } \\
\text { program translation of print material } \\
\text { into other languages. Volunteers are } \\
\text { "mobilised to implement the program" } \\
\text { but do not partake in the program itself. }\end{array}$ \\
\hline 18 & No & $\begin{array}{l}2 \text { types of volunteers: (1) those } \\
\text { people that do office or } \\
\text { administrative work and ( } 2 \text { ) those } \\
\text { people that participate in the } \\
\text { environmental programming - field } \\
\text { volunteers }\end{array}$ & - & - \\
\hline 19 & No & $\begin{array}{l}2 \text { types of volunteers: (1) those } \\
\text { people that do office or } \\
\text { administrative work and ( } 2 \text { ) those } \\
\text { people that participate in the } \\
\text { environmental programming - field } \\
\text { volunteers }\end{array}$ & - & - \\
\hline 110 & Yes & $\begin{array}{l}\text { Volunteers are those people help } \\
\text { with the office or administrative } \\
\text { work such as proposal writing. }\end{array}$ & $\begin{array}{l}\text { Participants are those people who } \\
\text { access and use environmental } \\
\text { education material offered by the } \\
\text { group over the internet. }\end{array}$ & - \\
\hline
\end{tabular}


In the case of $\mathrm{P} 2$ involving only the Chinese community the distinction between volunteer and participant did not arise during the interview. The term volunteer was used consistently. This was likely because the P2 does not have specific outreach programs and is more inwardly oriented, focusing on the training and development of its members. With P3, the City initiated volunteer program, key informant 13 made no distinction between volunteers and participants because the participants of the program were also considered to be the volunteers. In terms of P4, the urban agriculture program, key informant $\mathrm{I} 4$ also made no distinction between volunteers and participants for the same reason.

From the responses presented in Figure 17, it is evident that there is no rule that can be used to establish how environmental groups view volunteers and participants. Some groups view their volunteers and participants as one in the same. Other groups view volunteers as those individuals who give their time and skills for career advancement and Canadian experience in contrast to participants who are those individuals who partake in their programs.

This finding was unexpected and emerged as interviews with key informants were held. As this was recognised, I would often have to preface the interview questions by asking what the environmental group considered a volunteer versus a participant. Half of the key informants made specific distinctions between the terms volunteer and participant. Because of this, from this point forward the results of this study will also distinguish between participants and volunteers. In referring to participants I am referring to those individuals who participate in environmental programs offered by the environmental group. In referring to volunteers, I am referring to those individuals who contribute their time and expertise to the environmental group without participating in the environmental program.

\section{Information Gaps Exist: Ethno-cultural Data Not Collected}

Key informants were asked to speak about which ethno-cultural groups were involved in their environmental programs and the proportions which had been in Canada for five years or less. Answering these questions accurately proved to be difficult for the key informants. The most 
frequently cited reason for this was that this type of data was not formally recorded by the environmental groups. Responses to these questions, when given, were based on estimates provided by the key informant.

For example, when key informant I3 was asked about the ethno-cultural composition of participants in program $\mathrm{P}$, she stated:

"We don't ask, it doesn't matter...we ask what languages they speak."

However, from her own observation, key informant I3 offered that the ethno-cultural composition was mixed and while there was no predominant group, people from the Middle East, South and Central America, Europe, Asia and other parts of Canada were part of program P3. Key informant $\mathrm{I} 3$ also estimated that that about $75-85 \%$ of participants of program P3 were new immigrants to Canada. In commenting on why so many new immigrants participate in this environmental program, I3 stated:

"I think its kind of out there that you don't have to speak perfect English...the word is out in the community that this is a place for people who are newcomers to meet other newcomers."

Another reason that so many new immigrants to Canada participate in program $\mathrm{P} 3$ is perhaps because this environmental group is listed on the City of Toronto website. It is likely the case that the City website acts as a first resource for newcomers to Toronto who are looking for general information on various topics, including how to get involved with volunteering.

In the case of programs P6a, P6b and P6c the estimated breakdown of participants was as follows:

P6a: $60 \%$ Spanish $20 \%$ Somali $20 \%$ Others

P6b: $50 \%$ Spanish $20 \%$ Somali $20 \%$ Portuguese $\quad 10 \%$ Others

P6c: $\quad 70 \%$ Spanish $10 \%$ Somali $20 \%$ Others 
At the time of data collection, program P6c was in its planning stage and the ethno-cultural estimates were based on the estimates provided by I6 as to the results expected of the program.

Key informant $\mathrm{I} 10$ estimated that $10 \%$ of participants of the program P10 were new immigrants whereas about $50 \%$ of the volunteers doing administrative work at the environmental group's office were new immigrants. Key informant 110 also mentioned that the funding to have literature translated into different languages was not received, so that portion of the project was not implemented. If these materials were translated into different languages, it can only be hypothesised that the numbers of new immigrants participating in the program P10 would be higher.

For program P9, key informant 19 mentioned that Africans made up $60 \%$ of the participants, followed by Bangladeshis ( $25 \%$ ), followed by Latin Americans ( $10 \%$ ), followed by Canadians who had come to Toronto from other parts of Canada (5\%). Of the total number of participants, $50 \%$ had been in Canada for 5 years or less.

Programs P4 and P8 did not target specific ethno-cultural groups. Rather, the diverse nature of the programs' participants was a result of where the program was sited. Key informants, in speaking about these environmental programs noted that the mix of program participants was reflective of the population that was already present in the area. In the case of P5, ethno-cultural groups were also not specifically targeted and I5 used the term new Canadians to describe the participants of program P5. While key informant I8 could not comment on the specific ethnocultural breakdown of participants, she was able to estimate that $50 \%$ of the participants were new Canadians.

With P2, participants were all Chinese. No other ethno-cultural groups were part of program P2. This was the only group examined that was mono-cultural in composition.

It was evident that data specific to one's ethno-cultural background was not formally collected by the environmental groups examined. However, key informant $I 1$ pointed out that there were 
future plans for a survey to be distributed to the volunteers and participants to gain a better sense of which ethno-cultural groups were accessing services and partaking in programs. Key informant I1 stated that Italians and Portuguese were the largest ethno-cultural groups participating in the urban agriculture program. The second largest groups were from Latin America and Eastern Europe. He also added that even though there was a large Vietnamese population in the area, this group was not active in the urban agriculture program. Conversely, many of the participants in the urban agriculture program were Turkish but not many Turkish people lived within the vicinity of the garden. Key informant I1 estimated that $40 \%$ of volunteers for the urban agriculture program had been in Canada for five years or less.

When asked about the proportions of ethno-cultural volunteers involved in P4, key informant I4 stated that the volunteers were reflective of the area's population. Key informant I4 stated that the two largest ethno-cultural groups participating in the urban agriculture program were Chinese senior citizens and African Canadians. South East Asian and Caucasian volunteers were the second largest group.

In the case of $\mathrm{P} 7$, ethno-cultural data of participants attending energy conservation workshops was collected at a very basic level. Participants were asked to fill out an evaluation form rating the workshop. At the bottom of the evaluation form, Personal information such as name, contact information, age and ethno-cultural group are optional pieces of information that a participant can add or omit.

\section{Information Gaps Exist: Motivations Not Formally Collected}

The literature review detailed earlier identified various motivations for volunteering as presented by the 2000 NSGVP and discussed ethno-cultural specific data in the form of the Ethnic Diversity Survey. Other studies such as those by Donald (1997), Westphal (1993) Schroeder (2000) and Ryan, Kaplan and Grese (2001) presented motivations for volunteering in environmental activities. 
This study originally sought to find out what motivated ethno-cultural groups to participate in environmental activities. However, due to privacy and confidentiality regulations which were in place at various environmental groups, which precluded access to participant names and contact information, carrying out this study from that angle was not feasible. Because of this, project coordinators were asked to speak anecdotally from their own experiences about possible motivations. It was decided that motivation categories would not be given to key informants to get as wide a range of motivations as possible. The rationale for asking key informants about motivations was to discover whether knowing the ethno-cultural groups' motivations for participating in any way affected the types of interactions that occurred between the environmental and ethno-cultural groups during the planning and implementation of such interactions.

Because previous distinctions were made between volunteers and participants, this was also reflected in various responses to questions about why ethno-cultural groups decided to get involved with a specific environmental program. The responses are summarised in Figure 18.

It was thought that because the key informants were the individuals most closely associated with the program, they would be able to speak in depth and with ease about motivations. This, however, was not always the case. Key informants did not know the specific motivations because they had never asked or because participants and volunteers had never mentioned their motives for volunteering or participating. Because of this, responses detailed in the Figure 18 only reflect the opinions of the key informants and not the volunteers or participants themselves. 
Figure 18: Motivations for Volunteering and Participating

\begin{tabular}{|c|c|c|c|}
\hline \multirow[b]{2}{*}{$\underset{\text { Informant }}{\text { Key }}$} & \multicolumn{2}{|c|}{ Motivation(s) given } & \multirow[b]{2}{*}{ Quote / Paraphrase (if applicable) } \\
\hline & for Volunteering & $\begin{array}{l}\text { for Participating in } \\
\text { Environmental } \\
\text { Program } \\
\end{array}$ & \\
\hline I1 & \multicolumn{2}{|c|}{$\begin{array}{l}\text { Helping the community; to access healthy food; expand social } \\
\text { networks; make friends; to learn English }\end{array}$} & $\begin{array}{l}\text { "building a more aesthetically beautiful, tighter-knit } \\
\text { community." }\end{array}$ \\
\hline I2 & \multicolumn{2}{|c|}{$\begin{array}{l}\text { Key informant did not comment on individual motivations of } \\
\text { participants in program } \mathrm{P} 2 \text { becuse she never asked participants } \\
\text { about it. Spoke about her own motivations as being career } \\
\text { development or enhancement. She guessed that others probably } \\
\text { participated out of personal interest in environmental issues and } \\
\text { career advancement. }\end{array}$} & - \\
\hline 13 & \multicolumn{2}{|c|}{$\begin{array}{c}\text { Job skills, know about environmental issues from homeland, became } \\
\text { aware of environmental issues in Canada and would like to do } \\
\text { something positive for the environment }\end{array}$} & - \\
\hline I4 & \multicolumn{2}{|c|}{$\begin{array}{l}\text { To acquire skill; help the environment;access food; integrate back } \\
\text { into the community. }\end{array}$} & $\begin{array}{l}\text { "Building self-esteem, breaking the isolation, providing } \\
\text { healthy food and getting back to community activities." }\end{array}$ \\
\hline I5 & $\begin{array}{l}\text { Key informant did not comment on } \\
\text { individual motivations of volunteers. }\end{array}$ & $\begin{array}{c}\text { Key infomrant did not } \\
\text { comment on individual } \\
\text { motivations of } \\
\text { participants. }\end{array}$ & - \\
\hline I6 & For Canadian experience & $\begin{array}{l}\text { To learn about } \\
\text { environmental issues }\end{array}$ & - \\
\hline 17 & $\begin{array}{l}\text { To practice language skills; expand } \\
\text { contacts; network with others; a way to } \\
\text { settle in new country; a way to socialise }\end{array}$ & $\begin{array}{c}\text { To learn about energy } \\
\text { conservation; a way to } \\
\text { socialise; connect with } \\
\text { others of the same } \\
\text { culture; a way to help } \\
\text { the environment }\end{array}$ & $\begin{array}{l}\text { "Language- it's a way for volunteers to practice their } \\
\text { language and get their skills up and that's a real motivating } \\
\text { factor. By giving people experience in their field, if they are } \\
\text { interested in environmentalism, that's a motivating factor - } \\
\text { that they are in their field and it's part of their } \\
\text { résumé... They want to volunteer so that they can work on } \\
\text { their English so that they can work on their contacts, so that } \\
\text { they can network, it's really great way to get into a new } \\
\text { country" }\end{array}$ \\
\hline I8 & $\begin{array}{l}\text { People volunteered in the office for } \\
\text { Canadian experience and to learn English }\end{array}$ & $\begin{array}{l}\text { Ethno-cultural groups } \\
\text { participated in the } \\
\text { program because they } \\
\text { were familiar with } \\
\text { gardening from their } \\
\text { homeland and wanted } \\
\text { to continue that in their } \\
\text { new country of } \\
\text { residence. }\end{array}$ & $\mid$ \\
\hline 19 & $\begin{array}{l}\text { Interested in contributing to conservat } \\
\text { environment; to acquire exerience; to soc } \\
\text { diverse backgrounds; to h }\end{array}$ & $\begin{array}{l}\text { ion of the Canadian } \\
\text { alise with people form } \\
\text { ave fun }\end{array}$ & - \\
\hline I 10 & $\begin{array}{r}\text { To do something for the environment; to } \\
\text { for high school cred }\end{array}$ & xpand social networks; & - \\
\hline
\end{tabular}


Key informant 17 was the only one to mention that until now workshop evaluation forms for program P7 did not ask the reason for attendance but that for the next phase of the program, this information would be gathered so that workshops can be specifically tailored to the general motivations of attendees while keeping the overall environmental message.

\section{Local Level Interactions are Important}

A common characteristic among the environmental programs examined was that local contacts were used during the different stages of program planning and implementation. Local level thinking and local level action were apparent in different ways - recruitment through local contacts, the use of local media, the use of locally accessible venues and accessing English as a Second Language (ESL) classes. The following paragraphs detail these findings further.

\section{Recruitment}

As highlighted by the 2000 NSGVP the most frequently cited form of recruitment of volunteers (nation-wide and in Ontario) was that the organisation had asked them. The key informant interviews also revealed similar findings. A common trend among six of the programs examined was that key informants recruited their participants and did not wait for their participants to approach them. This was evident in P1, P6a, P6b, P6c, P7 and P9. In going out to recruit participants, these programs used language specific print material which was distributed to nearby schools, community centres, libraries or was published in local ethnic minority newspapers. The relevance in terms of local action is that these programs were marketed to local communities that were in close proximity to the program site or the environmental group's office.

Key informant Il recalled that in raising awareness about the urban agriculture program, brochures which were previously only available in English were translated into other languages which were reflective of the languages spoken by the residents of the area in which the urban agriculture program was operating. 
Key informants I6 and I9 used their ethno-cultural backgrounds to help with recruitment of participants for their programs. For example I6 used her ability to speak Spanish to recruit Spanish participants in all three programs $-\mathrm{P} 6 \mathrm{a}, \mathrm{P} 6 \mathrm{~b}$ and P6c. Somali participants were recruited by using someone from Somalia who was specifically recruited for that purpose. Key informant I9 used his African background to connect with local African business owners and built a rapport with them by frequenting their shops and using their services. He used this connection to recruit participants for the tree planting event (P9). Key informant 19 also personally went to local mosques to advertise the tree planting event. In speaking about finding volunteers for the implementation of P7 to the South Asian and West Indian communities, 17 noted that as a first step she accessed her own personal contacts and also contacted gathering places such as churches, mosques and community centres where South Asians gathered.

\title{
Finding an Ambassador or Representative
}

Key informant I5 suggested that finding a spokesperson for the environmental program from the specific ethno-cultural community which is being targeted is very beneficial:

\begin{abstract}
"It's all about partnering...we partnered with a really high profile Chinese businessman... without him we would have not gotten in Ming Pao, the largest Chinese newspaper... he got World Journal to come out, he had Omni Television come out and this all came up because we had a spokesperson for us. I tried calling these newspapers and I did not get through to anybody."
\end{abstract}

Another benefit of using an ambassador is that it helps to encourage other members of the same ethno-cultural group to get involved. The use of local representatives was also highlighted by key informant 15 in reference to interactions with the Hindu community which arose when I5's colleagues noticed that coconuts and other organic materials such as flowers were being placed in a local river. After conducting some research, it was found that the Hindu community was making religious offerings to the watercourses where they lived. While these items were organic and did not pose an immediate threat to the watercourses, these items were often being left in plastic bags which were not organic and which could harm species living in and adjacent to the watercourse. To address this matter, key informant I5 initially called a Hindu Temple in the vicinity of the watercourse but was not received well by the priests, as they were under the 
impression the government was calling them about something they were doing wrong. Key informant recalls:

\footnotetext{
"It's very difficult to make those cold connections...I had to meet the priests one-on-one... when we met face-to-face, it was a lot easier...[priests] are the familiar face...the community leader, well respected, they know their community and know what will work."
}

In meeting with the Hindu priests key informant I5 was able to discuss the issues of the water offerings with them and together they were able to develop a suitable course of action. For example, it was decided that the priests, instead of key informant 15, would provide the congregants with updates and information about how their water offerings could be modified while keeping within their traditions so that the watercourse would not be harmed.

Key informant 15 recounted another similar issue that arose with the Chinese community. According to key informant I5, the Chinese community is known to be very interested in fishing. Colleagues of 15 came to know that live bait was possibly being released into watercourses along with other invasive or non-native fish species. In addressing this matter key informant I5 said:

"We are going to follow the same model because it has worked really well in connecting with those main community leaders - maybe it's the Chinese business council, maybe it's the local Chinese settlement agencies...I'm forming a committee where we can together come up with solutions."

Key informant I7 also spoke about replicating the local spokesperson technique for Phase II of program P7 which will focus on the South Asian and West Indian communities. Currently 17 is in the process of identifying potential spokesperson(s) by doing background and demographic research about these communities in Toronto. Key informant I5 stated:

"So we know for the next phase, we will have to have an ambassador like that, that if we want to get any type of media, we need to have a spokesperson, [you]can't just go out and do it yourselves." 
Another form of local level connections was getting local politicians involved in the environmental program. This was done in the case of program P7. Key informant I7 stated that she contacted the local Member of Parliament's (MP) office to advertise a workshop and asked if the MP would send out an email about the workshop to his nearly 3,000 constituents. By doing this, key informant I7 learned that local MPs are supposed to promote energy conservation to their constituents as part of their mandate and so by partnering with the local MP, it became a win-win scenario where 17 was able to access the MP's constituent email list and the MP was able to use the workshop as a platform to promote energy efficient programming in his riding.

In the past $\mathrm{I} 9$ has also used local politicians to leverage media coverage of various events. For example, Barbara Hall, Toronto's former Mayor was invited to the opening ceremony of the environmental group. As well, key informant 19 mentioned that in the past George Smitherman, another local politician was invited to attend events to make participants feel more connected with their neighbourhood. The attendance of local politicians also fostered a sense of recognition and pride in participants.

\section{Local Media: Radio, Television and Newspapers}

Similar to Donald's (1997) study which noted that the Task to Bring Back the Don advertised in local ethno-cultural newspapers and the suggestions for working with ethno-cultural groups presented in the TRCA's educational video Human Connections, the use of ethno-culturally specific media was used in P7 and P2. In program P7, the previous section detailed how the use of an ambassador led to increased print and television media coverage. For program P2, participants from time to time delivered a Chinese broadcast on a Chinese radio station to raise awareness about environmental issues. Other ways in which environmental groups accessed local resources was through fairs and festivals. Both key informant I2 and I5 noted that their respective environmental groups in the past had attended local fairs and festivals (planned by other groups) to promote their environmental programs.

Aside from print, radio and television exposure, all of the environmental groups had a website from which information about the organisation and its programs could be accessed. Most of 
these websites listed information in English only. The two exceptions were the websites from the environmental groups who ran programs $\mathrm{P} 2$ and $\mathrm{P} 7$, which both posted information in Chinese.

\section{Locally Accessible Venues}

Some of the environmental programs took place in areas that were locally accessible to participants. For example, with program P8, the gardens were located in ethno-culturally diverse neighbourhoods and participants of the program did not have to travel far to attend tree planting or gardening sessions. Key informant I6 stated that the naturalisation, planting and gardening projects that were part of program P6a were geared to local residents who would be frequenting the gardens the most. Key informant $I 7$ also commented that as part of program P7 workshops were held in a community centre in a Chinese neighbourhood to increase attendance of Chinese participants. As part of program P5, geared at creating environmental experiences for new Canadians, key informant I5 noted that visits to conservation areas and the maple sugar bush sites were organised in such a way that residents living in those areas would attend. The rationale behind this was that if the environmental experience is provided to a family or person that lives in the vicinity of the program site, the odds of that family or person revisiting that site on their own increases because the site is locally accessible to them.

\section{Accessing ESL Classes}

Similar to the suggestion in the TRCA's Human Connections video, it was found that as part of three programs ESL classes were visited or taken out on field trips as a way of fostering environmental outreach and education. Key informants 15, I7 and I8 spoke about using ESL classes in this way. The advantage of going into an ESL class, according to I7 was that it provides a "built-in audience" to which environmental education can be targeted:

"The biggest lesson learned was putting this [energy workshop] into English as a Second Language classroom. There was so much of the programming that it was a win-win. For instance, we sent publications ahead of time... and they [the students] ended up translating one of the publications as part of their program - they got the students to do that...they translated from Chinese to English...there are so many ESL schools, it's endless." 
Key informant 18 spoke briefly about taking an ESL class out for a tour of the gardens as a learning activity outside of the classroom. Key informant I5 also referred to taking ESL students on an outdoor education trip to a sugar bush site or subsidising visits to community events held at conservation areas such as fishing festivals or maple syrup festivals.

\section{Environmental Programs are Multi-faceted}

The environmental projects examined for this study can be classified into different types of stewardship activities. Lerner writes that stewardship activities can be classified into two main types of activities - basic or adjunct. Basic stewardship activities refer to advocacy, conservation, education, monitoring, preservation and restoration. Adjunct stewardship activities refer to fundraising, remedial action plan participation and research. Education was the most frequent type of stewardship cited by key informants. This was not an unexpected finding because logically, learning about a new concept or issue precedes taking action. The following paragraphs examine the multi-faceted nature of the environmental programs more closely.

Program P6a was specifically targeted to Somali and Spanish newcomers to Canada. This program involved three different yet connected activities. The goal of the first activity was to educate the Somali and Spanish newcomers about ecological naturalisation, gardening and the plant cycle. The second activity was referred to as an "action day" during which the program participants used their new knowledge about naturalisation and planting to carry out hands-on local projects. The third part of the program involved a recreational component such as a discovery walk or a canoe trip designed to celebrate the accomplishments of the participants during the action days.

In program $\mathrm{P} 6 \mathrm{~b}$, the goal was to raise awareness about climate change. This program was also geared to Spanish and Somali newcomers to Canada. Italian and Portuguese newcomers also participated in the program. This program developed education materials that presented 10 simple steps that could be taken to reduce energy consumption and greenhouse gas emissions. A recreational and educational component was also part of this program. For example paddling 
trips were organised so that participants could experience a new sport as well as make positive connections between clean air and water. This deliberate pairing of educational and recreational activities fosters formal and informal learning respectively.

Building on the previous two programs, program P6c, focuses on educating the Spanish and Somali communities about the One Tonne Challenge. This program is currently in the process of recruiting and training trainers who will facilitate workshops to educate the Spanish and Somali communities.

Organising celebratory or recreational events as part of an environmental program is not unique to P6. Program P3 has an annual garden opening ceremony at the beginning of the planting season as a way to motivate participants and instil a sense of commitment to the urban agriculture garden. Similar celebrations also occurred as part of P1's urban agriculture program. Festivals that celebrate the Chinese New Year, Black History Month and other cultural holidays are regularly planned as part of the group's commitment to celebrating the diversity of its constituents, to bring them together and to motivate them.

Key informant I7 pointed out that for the pilot phase of program P7 the Chinese community was involved from the planning phase through to the implementation phase of the program. For example, during the planning phase, volunteers were recruited specifically from the Chinese community to take part in a focus group that was held to learn more about the community and inform the direction of the program.

Program P5 also focused on developing environmental and associated recreational experiences for newcomers to Canada. Although these environmental experiences were recreational based they were deliberately designed to foster positive stewardship and environmental ethics. Key informant 15 said that the recreational trips to conservation areas for newcomers to Canada always incorporate a conservation theme so that not only do the participants experience a new recreational activity but they also learn about environmental issues. This resonates with comments by key informant I8 who said, "We always have some learning component so that it is 
interesting." These learning components could include a tour of the garden, learning about native species and learning techniques of transplanting plants.

Key informant 19 noted that for program P9 as part of a closing ceremony participants were given certificates of recognition to celebrate their accomplishments.

\section{Environmental Groups Do Not Work in Isolation}

A common trend was that all of the environmental groups consistently worked with other groups for fundraising, planning, implementation and idea sharing for each of the projects examined.

In terms of fundraising the only program that did not have to apply for external funding was P3, which was fully funded by the City of Toronto. The program received no federal or provincial financial support. However, key informant $\mathrm{I} 3$ indicated that she was often approached by external groups such as the TRCA, Hydro One and Consumers Gas that wanted to present workshops to the participants of program P3. In this way, program I3 worked with other groups.

Among all of the other organisations, Trillium Foundation, TD Friends of the Environment and Eco Action Canada were the most commonly cited funders of the environmental programs. It is interesting to note that program P2 was operated by the only non-registered group and because of this the group could not apply for national or provincial funding. Instead program P2 focused more on the personal contacts or affiliations of its members. For example, many participants of P2 volunteer with other organisations such as the Boy Scouts and the Cancer Society of Ontario.

By using these personal affiliations the participants of P2 were able to leverage resources. Key informant 12 mentioned that meetings or training sessions are often held in a church hall because one of the members of P2 is able to get a special price on the rental of the hall and if they were not able to get this special price they would not be able to afford the rental costs. Key informant I2 also noted that a nominal membership fee is collected from group members which supplements the income earned from translation services provided to other groups. None of the 
other key informants mentioned that their interactions with ethno-cultural groups included having them fundraise for the group or the program.

For programs P1, P4 and P8 which focused on urban agriculture and gardening, key informants I1, I4 and I8 acknowledged that the City of Toronto Parks and Recreation Department was an instrumental partner because these environmental groups do not own the land on which their programs occur. The City of Toronto donated the gardening spaces to these groups. Key informant I1 also noted that the City of Toronto helped construct a path that would make the urban agriculture gardens of $\mathrm{Pl}$ wheel chair accessible. The City of Toronto was also helpful in providing material resources to these groups. Key informant 18 noted that the City of Toronto had donated two gardening tool boxes and a garden shed to the urban gardening project. Citing the importance of partners, she added:

"Partners are essential. It's like divide and conquer. Share the burden. Sometimes your partner will have more knowledge and experience and it's a better way of getting stuff done than to assume it all on your shoulders."

Key informant 19 noted that for program P9, he worked closely with the Taskforce to Bring Back the Don who provided technical assistance in the form of training for program participants along with material support in the form of gloves, shovels and other tools that the participants required on the day of the tree planting event. Key informant $\mathrm{I} 10$ noted that if he was working alone on this program, he would not have been able to purchase the correct species of trees needed because only the Taskforce had access to the main supplier of the trees. The Taskforce also had the resources to coordinate the storage of trees before the planting day and organised the transport of the trees to the planting site on the day of the event.

Aside from looking to other organisations for funding and material support the environmental groups also look to other groups for recruitment of program participants, especially in cases where specific ethno-cultural groups were being targeted. For example, key informant 16 looked to two formal ethno-cultural groups - the Somali Women and Children Support Network and the Spanish Senior's Group for programs P6a, P6b and P6c. These programs were marketed 
specifically to these organised groups. Key informant I6 also marketed the programs to organised neighbourhood groups such as the Harbourfront Community Centre and the Dundas West Residents Association.

In every key informant interview the name of at least one other environmental group or key informant included in this study was mentioned. This served as an indication that key informants were aware of other environmental groups in their domain. However, this does not indicate that these key informants were aware of each others' best practices and techniques for encouraging ethno-cultural groups to participate in environmental activities.

For example, program $\mathrm{P} 7$ received help from the environmental group that operates program P2. During the planning phase of P7, key informant 17 approached key informant 12 for help with the translation of an English brochure into Chinese. A workshop which was part of P7 was held at the community centre that operates program P4. Key informant I10 mentioned P7 and the efforts this program made to target specific ethno-cultural communities and added that program P10 did not want to replicate those efforts but would prefer to use I7's environmental group as an ally.

\section{Funding Affects Long-term Program Planning}

Key informants indicated that funding is a driving force that affects environmental programs, especially long-term program planning. This finding builds on the discussion of funding which was presented in the previous section. Aside from the P2 which did not apply for external funding and P3 which was fully funded by the City of Toronto, other environmental groups commented on the nature of funding and its impact on program sustainability.

In the case of program P6a, key informant I6 stated that "we wanted to continue with our [ecological] naturalisation program, but Eco Action said 'no'." She also stated that she could not continue with program P6b because funding was no longer available for general climate change awareness. As a result, she was tied to promoting the One-Tonne Toronto (OTTO) ${ }^{2}$ program if

\footnotetext{
${ }^{2}$ OTTO is the city-level campaign of the One-Tonne Challenge.
} 
she was to obtain any funding. Since her environmental group was already promoting climate change awareness through program P6b she adapted that program and created program P6c. Because she was able to link program P6c to the program objectives of OTTO she secured yearlong funding.

Key informant 110 echoed the comments of key informant I6:

"You know when there is talk in the government and in the funding, that you have to mobilise, you have to position yourself to be able to do what you need to do, to do what you are already doing or to fill that gap and be able to access funds, because a lot of the funders follow trends"

Program P9 was a one-time program because of funding constraints. Key Informant 19 suggested that funding is a key determinant of how long a program runs. Once the funding runs out, it is hard to keep the program running especially because funding requirements may change from year to year and especially with changes in government. Key Informant I9 also added that because funding is for a limited period it is often given with the intent that once the funding ends the program should be able to sustain itself without additional funding. Being able to sustain such a program is challenging for a small environmental group like the one P9 represents:

"Sustainability - it's not easy. It's not easy to mobilise resources and people".

Key informant 18 also spoke about how environmental programming is influenced by funding requirements. She suggested that at the time of the Millennium, there was funding support for environmental programs that involved ethno-culturally diverse groups:

"When these gardens were conceived, part of the mission was to choose sites where new Canadians probably would be living... sites where they might not have their own gardening space... we definitely looked for areas where new Canadians were gathering."

Key informant 15 mentioned that funding requirements forced program P5 to shift its focus to creating environmental experiences for new Canadians as opposed to continuing to create 
environmental stewardship opportunities such as workshops and tree planting events for new Canadians because these activities were already being implemented through other divisions of the environmental group.

\section{Ethno-cultural Sensitivity is Important}

Key informants revealed that in order to encourage ethno-cultural groups to participate in environmental activities ethno-cultural sensitivity was important. This was especially true for programs that targeted specific ethno-cultural groups. Key informants I6 and 17 commented about ethno-cultural sensitivity during the planning and implementation of programs P6a, P6b, P6c and P7. They both elaborated on the fact that background research that is specific to the ethno-cultural group being targeted was critical in making participants feel welcomed and comfortable during the environmental program. Key informant 17 mentioned that as part of a focus group in preparation for the implementation of program P7, she organised a Chinese dessert so that Chinese focus group members would feel comfortable. She added "as much as you can tailor it [the environmental activity] to the ethno-cultural group the better."

Key informant I6 also commented about ethno-cultural sensitivity in relation to food. In planning program P6a, key informant 16 did not realise that the Somali women participants did not eat pork and meat which was not halaal. In her first workshop with the Spanish and Somali participants, I6 organised sandwiches for lunch which were not well received by the Somali participants but which the Spanish participants liked. From that experience, I6 learned that the Somali participants prefer to prepare and bring their own food as opposed to having it provided for them. Traditional African music was played during meetings and training sessions by key informant $\mathrm{I} 10$ to foster a sense of comfort and familiarity for participants of P10 who were from Africa.

In terms of program P1 ethno-cultural sensitivity was shown by the types of vegetables that were grown in the garden. Key informant $I 1$ mentioned that vegetables like calalloo (native to the Caribbean) and tomatillos (native to Latin America) were grown in the urban agriculture garden. 
Key informant II added that he also catered to users of the food bank by making available items that were ethno-culturally specific. He mentioned that because he knew Muslims, who do not eat pork, used the food bank, he applied for and received a grant to buy foods such as lentils and other ethno-cultural specific foods that were preferred by the Muslim users of the food bank.

Ethno-cultural sensitivity was also shown by the environmental groups that published materials in different languages to accommodate participants who may not be fluent in English. The celebration of different ethno-cultural holidays which have been previously discussed also shows ethno-cultural sensitivity. Key informants I6 and I7 also commented that having a facilitator that is from the same ethno-cultural group as the target audience is a technique that they have used to create a sense of familiarity among program participants because seeing someone of the same ethno-cultural group delivering the environmental message makes the message less foreign. Another way that environmental groups attempted to be ethno-culturally sensitive was through the provision of translators. For example, key informant I7 stated at the Chinese energy efficiency workshop she arranged for a translator to be present in case someone participating in the session needed interpretation in Chinese.

Key informants did not reveal that ethno-cultural groups were deliberately targeted with the intent that all ethno-cultural groups should have exposure to the environmental movement. For example, I5 commented that the CDMES program was originally developed by the TRCA as a result of an observation that program participants were not reflective of Toronto's diverse population. This shows that ethno-cultural sensitivity was important from the perspective of the targeting ethno-cultural groups for inclusion in environmental activities. However, key informants did not specifically reveal that ethno-cultural sensitivity in the form of exposing all ethno-cultural groups to environmental issues was an overall core value for their program or group. 


\section{Discussion and Summary of Key Points}

In this chapter the findings of the ten key informant interviews were presented in detail, as they relate to the research question: How are environmental groups encouraging ethno-cultural groups to participate in environmental activities in Toronto. The findings were presented that relate to the planning and implementation of the environmental programs examined in this study. Eight major findings were discussed and are summarised below:

1. The meaning of the terms volunteers and participants can vary according to each environmental group. Some environmental groups view volunteers and participants as the same whereas other environmental groups distinguish between volunteers and participants. Volunteers are those individuals who do unpaid work for the group and do not take part in the environmental program. Participants are those individuals who participate in the environmental program but who do not contribute to the planning of the program.

2. Ethno-cultural data is not collected by environmental groups. When asked about the ethno-cultural proportions of participants and the proportion of participants who were new immigrants, key informants were only able to provide estimates.

3. Ethno-cultural groups who participate in environmental programs or who volunteer with the environmental group are also not formally asked about their motivations for doing so by the environmental group. General motivations for volunteering offered by the key informants were to practice English and to expand one's network of friends. Motivations for participating in environmental programs were to help the environment and learn about environmental issues. In some cases key informants did not distinguish between motivations of volunteers and participants.

4. Funding affects long-term program planning. Only one of the environmental programs examined did not have to apply for funding. All other programs were impacted by funding requirements, which stipulate the aim and focus of environmental programs. 
Non-governmental funders are aware of the political environmental agenda and their funding requirements tend reflect this. Funding is only given for a limited period of time after which the program is required to become self sustaining. If the program is not sustainable without future funding, the program ends. Because of this, long-term program planning is difficult for environmental groups.

5. Environmental programs are multifaceted in that they exhibit the deliberate pairing of educational and recreational activities. Recreational activities allowed for the program participants to reflect about what they have learned and make their own connections between the recreational activity and the environment. Celebratory events were also part of environmental programs which offered the participants a way of being recognised, appreciated and motivated.

6. Local level interactions are important. Local level interactions occurred particularly during the planning phase of the environmental programs examined. For example, local ethno-cultural newspapers, radio stations and television channels were used to promote environmental programs. Also, local schools, libraries, community centres, mosques and churches were approached to recruit participants for the environmental programs examined.

7. Environmental groups do not work in isolation. All programs examined in this study received external support from other groups. External support in most cases was in the form of funding. Another form of external support included asking organised ethnocultural and neighbourhood groups for participants and volunteers for the environmental program.

8. Cultural sensitivity is important when planning and implementing environmental programs involving specific ethno-cultural groups. Ethno-cultural sensitivity was shown by providing ethno-culturally specific foods, making print material available in languages other than English and by having program facilitators that were of the same ethnocultural background as the target audience. 
The following chapter will discuss the implications and importance of these findings. 


\section{Chapter V: Analysis}

This chapter provides a discussion of the implications and the importance of the major findings detailed in the previous chapter. This chapter is therefore a critical examination of the findings as they relate to the research question: How are environmental groups encouraging ethno-cultural groups to participate in environmental activities in Toronto?

\section{Expanding the Definition of Volunteer Environmental Stewardship}

As discussed in the first chapter, volunteer environmental stewardship refers to "activities that contribute to the protection of a special area or feature of the natural environment by people who give their time and effort on a voluntary basis" (Lerner and Reid, 1993: 108). The findings of this study suggest that this definition should be expanded to include non-tangible resources such as energy, the conservation of which was the focus of programs P6b, P6c, P7 and P10. Furthermore, this definition should also be expanded to include stewardship efforts that are occurring within urban households away from natural settings such as streams, lakes conservation areas and green spaces. The traditional meaning of the word stewardship refers to managing household affairs. Program P6b, P6C and P7 focused on educating participants on how to make simple changes in their daily lives that would result in benefits to the environment. The voluntary conservation of energy and the monitoring of results in terms of monetary savings are new forms of stewardship which are being promoted at the household level. Conservation and monitoring in this case are being used outside Lerner and Reid's definition of stewardship activities but with the similar intent of environmental protection. The alteration of the definition of volunteer environmental stewardship will acknowledge that civic environmentalism and active earth keeping are occurring in urban areas at the local level by individuals and households.

The expansion of the definition of volunteer environmental stewardship should also recognise that there are differences between volunteers and participants. The findings of this study suggest that in some instances volunteers are those individuals who do not take part in environmental programs but who do the preparatory work for the program such as proposal writing and other administrative tasks required by the environmental group. In contrast participants have been 
cited as being those who take part in the environmental program without contributing to the background work needed to plan and implement the program itself. Perhaps the use of the word voluntary instead of volunteer would be better suited to describe environmental stewardship regardless of the way in which an environmental group defines participants and volunteers.

Given these reasons for the expansion and alteration of the definition volunteer environmental stewardship this new definition is proposed:

Voluntary environmental stewardship refers to voluntarily engaging at the local level in environmental activities that contribute to the protection, restoration, preservation, conservation and monitoring of the tangible resources of the environment such as water, land and trees as well as the non-tangible environmental resources such as air and energy.

\section{Exploring the Relationship between Funding and Environmental Programming}

The findings of this study suggest that the environmental programs examined except one (P3) are impacted by funding, especially in terms of long-term program planning. Key informants stated on numerous occasions that funding prescribes the focus and intent of environmental programming. In turn it was also found that funding for environmental programs is influenced by the current political environmental agenda. The Kyoto Protocol, reducing greenhouse gas emissions and energy conservation are the buzz words when environmental issues are discussed in the current Canadian political realm. This is also evident by the mass media promotion the One-Tonne Challenge is currently receiving.

In contrast, environmental programming at the time of the millennium was specifically geared to the inclusion of ethno-cultural groups, as indicated by I6, I8 and I9. Key informant I5 also spoke about how the CDMES program received funding with the intent that ethno-cultural groups would be included in environmental programming. If funding was the primary factor which helped or hindered environmental groups' efforts in encouraging ethno-cultural groups to participate in environmental activities then it can be hypothesised that environmental programming at times was occurring without the core intent of inclusion of ethno-culturally 
diverse participants. Rather, that if funding required an ethno-culturally diverse group of participants, then including these groups in environmental programming would guarantee funding for the environmental groups.

However, my interviews with the key informants lead me to believe this was not the case. The key informants were passionate about the environmental programs they were being interviewed about and including ethno-cultural groups in their programming was never spoken of as a drawback. It was, on the contrary, something that added excitement to the programming by being able to work with different participants. It was also evident that if funding was structured differently the programs which have ended would still be operating.

\section{Deliberate Targeting and Deliberate Siting}

The ways in which ethno-cultural groups became involved with the environmental programs can be classified in two ways. The first is by deliberate targeting and the second is by the deliberate siting of the environmental program in an ethno-culturally diverse area. By deliberate targeting I am referring to programs that used language specific marketing to attract a specific ethnocultural group, as was the case in program P7. In contrast to this the urban gardens in program P8 were sited in ethno-culturally diverse areas in the City of Toronto. Language specific marketing (other than in English) was not used to recruit participants for P8. Rather, it was the deliberate siting of the gardens in the area that brought the ethno-culturally diverse participants to the program.

Deliberate targeting and deliberate siting are not mutually exclusive. These two techniques can be used together to heighten participation of ethno-cultural groups in environmental programming. For example, in program P7, energy conservation workshops geared to the Chinese community were held in a Chinese neighbourhood so that area residents would be more likely to attend. The program was also marketed in Chinese to the same Chinese neighbourhood to increase the number of Chinese participants. 
Given this example, it is likely that deliberate siting of environmental programs without deliberate targeting would reduce the number of participants from the targeted ethno-cultural group. It might be the case that without specifically targeting the Chinese community even though a workshop is held in a predominantly Chinese neighbourhood, the turn out of participants may not be predominantly Chinese, but more reflective of the mix of residents living in the area.

In the case of the urban agriculture program, $\mathrm{P} 1$, the environmental group running this program was located in ethno-culturally diverse neighbourhood and because of this, deliberate targeting was used to attract and encourage the local residents to participate in the program. In this example the location of the environmental group preceded deliberate targeting of ethno-cultural groups.

Program P5 which focused on creating environmental experiences for new Canadians also used deliberate siting, though not to attract ethno-culturally diverse participants. Deliberate siting was used so that local area residents would be taken on trips to conservation areas, sugar bushes or picnic sites that were in their neighbourhood. It was illogical to key informant I5 to provide such trips to participants who would not be able to access the site again on their own. In this example deliberate siting was used to select program sites that were locally accessible to program participants. These sites were also deliberately selected because they would provide new Canadians with an experience that was 'Canadian' which they would not have previously experienced anywhere else.

\section{Active and Passive Forms of Interaction}

The previous chapter described ways in which the environmental groups encouraged, recruited and interacted with the ethno-cultural participants of its programs. Upon closer examination, these techniques can be classified as either passive or active. 
I would classify, for example, the use of websites as a form of passive interaction. All of the environmental groups in this study had a website which provided general and specific information. I refer to this as a passive interaction because the information exchange when viewing a website is only one-way. That is, from the website to the individual accessing the site. The use of the internet is a quick and efficient way of conveying information to an unlimited number of people but it does not facilitate two-way interactions between potential participants or volunteers and the environmental group.

I would argue that the most passive program examined in this study would be P10, which was primarily internet based and as a result, there was minimal interaction between the program coordinator and the participants. In terms of monitoring energy savings and conservation, participants were self-regulated because they were required to fill out monitoring logs online. Key informant $\mathrm{I} 10$ mentioned that his primary interaction with participants of program P10 was over the telephone, if they called him with questions about the program.

In contrast to this, I would classify meeting face-to-face with formal ethno-cultural groups, as key informant I6 did with Spanish and Somali participants, as an active interaction. Face-to-face interactions allow for personal contact during which emotions and nuances can be sensed and explored further. Face-to-face interactions also allow for direct feedback because conversation can flow back and forth between individuals, representing two-way information exchange. This was highlighted by key informant I5, in recounting her experience with the Hindu priests, who over the telephone perceived her inquiry to be about a criminal offence they unknowingly committed.

The multi-faceted nature of the environmental programs examined in this study was discussed in the previous chapter. Programs such as P5 and P6b show that active and passive interactions can be combined to diversify programming. For example, active interactions would be those in which participants are formally exposed to new environmental concepts such as energy saving techniques during a workshop or by attending a session to learn how trees benefit air quality. Passive interactions would be the recreational-type activities such as visits to the sugar bush or a 
paddling trips during which participants are not formally learning environmental concepts but are left to make their own personal connections between the leisure activity and the environment.

The use of language specific print media, I would argue has the potential to be both active and passive, depending on how it is distributed. For example, if language specific materials are left at a display booth or on a shelf at a community centre to be picked up, I would classify that as a passive way of advertising an environmental program or encouraging participants to get involved. In comparison, if language specific materials are distributed to organised ethnocultural groups gathered at community centres or ESL classes this would represent an active interaction because there is face to face contact, where two-way information exchange can occur.

\section{Environmental Discourse: Integration and Assimilation}

Returning to the discussions of environmental concern, integration and assimilation that were presented in the introductory chapters this section discusses the way in which the environmental programs examined convey environmental messages to ethno-cultural participants. To briefly reiterate, integration in terms of immigration refers to the process of merging one's traditional customs and beliefs, from their homeland, with those of their new country of adoption. Conversely, assimilation refers to the process of giving up one's traditional customs and beliefs and replacing them with those of the predominant ethno-cultural group. The notion that individuals use their cultural filter to interpret and solve environmental problems was also previously highlighted.

In this section I argue that although environmental groups are showing ethno-cultural sensitivity in ways such as doing background research about ethno-cultural groups in terms of their general preferences, they are not approaching the environmental discourse from the perspective of the targeted ethno-cultural groups. For example, none of the environmental programs that specifically targeted ethno-cultural groups included a component in which a discussion about environmentalism was framed from the viewpoint of the ethno-cultural participants. Instead, environmental discourse was the same as if it were geared toward the mainstream population. 
The only difference was that print material may have been published in a language other than English and in some cases a translator was present. Despite these adaptations, the environmental message conveyed and approach taken by the environmental groups remained unchanged.

Because of this, it appears that environmental groups are tending to assimilate the environmental values and perspectives of their ethno-cultural participants as opposed to integrating them into the groups' normal practises or learning from them. I am not proposing that environmental programs be held to simply learn about the environmental values and beliefs of specific ethnocultural groups. I am, however, suggesting that starting an environmental program by asking the ethno-cultural participants about their traditional forms of environmentalism as related to the environmental message being promoted, will add cross-cultural awareness and new perspectives to the mainstream environmental ideologies, similar to Kato's (2002) suggestion.

This type of cross-cultural awareness can be added to environmental programs by asking the ethno-cultural participants about their lives in their homelands. For example, my mother, who grew up in Kenya was never exposed to formal recycling programs like the one Toronto has. However, if I were to start a discussion with her about how she grew up in a three bedroom house with her parents and six siblings, stories of recycling and reusing clothing and conserving water by taking baths with one pail of boiling water instead of filling up the whole tub would quickly surface. These types of personal experiences, I would argue, form a practical springboard from which Canadian environmental issues such as recycling, reducing greenhouse gas emissions and urban pollution can emerge in a way that is ethno-culturally appropriate and sensitive. This type of approach allows for traditional non-Canadian forms of environmentalism to emerge while at the same time by linking them to environmental issues that are current and require local action.

Gosine (2003) and others have argued that because environmental issues are not framed in ways that ethno-cultural groups can relate to they tend not to participate in the mainstream environmental movement. I would argue that if this is the case, starting from the perspective of the traditional environmentalism of different ethno-cultural groups seems like a logical way to 
integrate these groups and their environmental perspectives into mainstream environmental discourse while at the same time encouraging them to participate in current environmental issues. This type of environmental discourse can only occur if ethno-cultural groups are attending environmental programs and the use of deliberate siting and deliberate targeting can facilitate this.

Accessing ESL classes is one technique that the environmental groups used to obtain specific ethno-cultural audiences that were newcomers to Canada. The rationale for accessing ESL classes was that not only does it provide a curriculum for the ESL class but it also provides a forum in which environmental groups can market their programs and raise awareness about specific environmental issues. In targeting ESL classes, environmental groups are recognising that they can reach newcomers to Canada and they can teach them about environmental issues at the same time as they learn English. This seems like an ideal situation for environmental groups who are encouraging newcomers to Canada to participate in their environmental programs. However, I would argue that if the environmental issues are not presented in an ethno-culturally relevant manner the environmental issues might be perceived by the ESL students as foreign. The manner in which the environmental education material is being presented to ESL students by environmental groups was beyond the scope of this study but can be explored in future studies.

\section{Addressing the Data Gaps}

The interviews with key informants revealed that ethno-cultural data of participants or volunteers is not formally collected. When asked about the ethno-cultural breakdown of participants, key informants provided only their best guesses of the proportions of ethno-cultural groups and the proportions which have been in Canada for five years or less. The introductory chapters detailed that there are differences between Canadian-born visible minorities and new Canadians or immigrants. These differences should be considered when planning and implementing environmental programming. One fundamental difference is that a Canadian-born visible minority would be able to speak English whereas a new immigrant may or may not be able to speak English. If these types of data are not recorded by environmental groups then it is likely 
that the planning and implementation of environmental programming geared at ethno-cultural groups may become less effective. For example, if an environmental program is geared to new immigrants then the provision of a translator would be advantageous. In contrast to this, if the program is geared to Canadian-born visible minorities then a translator would not be necessary.

However, this rule does not always apply to all techniques of ethno-cultural sensitivity previously highlighted. For example, it is likely that both Canadian-born visible minorities and immigrants would benefit from and appreciate an ethno-cultural specific snack as part of an environmental program. Furthermore, beginning the program with a discussion of non-Canadian forms of environmentalism would be relevant to new immigrants and might be something which Canadian-born visible minorities can learn from.

When encouraging and specifically targeting ethno-cultural participation in environmental programming, it is important that environmental groups consider whether they are targeting new immigrants or Canadian-born visible minorities as this factor will influence other aspects of the program such as location, forms of media, the language it is published in and the contacts used. For example, a program for new Canadians could be marketed to religious groups or settlement organisations in languages other than English whereas an environmental program for Canadianborn visible minorities might be better suited to be marketed only in English in mainstream newspapers and on mainstream radio stations.

Another data gap arose when trying to determine the motivations that ethno-cultural groups had for participating in the environmental programs examined. Key informants were only able to offer their perspectives of possible motivations because they had either not asked participants their motivations for becoming involved or because the participants had not told them their personal motivations.

Previous literature reviewed in this study noted that knowing what motivates volunteers enables program marketing and recruitment to be done more effectively. In addition knowing the motivation volunteers have for getting involved can also help to direct programming. In the case 
of the environmental programs examined, motivations were not formally collected. I would argue that as environmental groups become more sophisticated in working with ethno-cultural groups and subgroups like new Canadians and Canadian-born visible minorities, ethno-cultural data as well as motivations for volunteering or participating will be gathered and used to direct environmental programming. Inklings of this trend emerged with two key informants - I1 and I4.

Key informant Il mentioned that he will be collecting ethno-cultural specific data to gain a better sense of the ethno-cultural groups that are using the programs and services offered by his environmental group. He also mentioned that a diversity and strategic planning committee had been established as part of the internal structure of the environmental group to ensure that issues surrounding ethno-cultural diversity are examined in all levels of programming and not just with the urban agriculture program. Key informant I4 also noted that one of her colleagues handles diversity issues. Further explorations into the structure of environmental groups would reveal how and at what levels issues of ethno-cultural diversity are being handled.

\section{Including or Segmenting}

Various environmental programs examined in this study have shown that ethno-cultural groups are being encouraged to participate in the environmental movement in Toronto by being specifically targeted and by the deliberate siting of environmental programming in areas where these diverse groups reside. While direct targeting of specific ethno-cultural groups is a technique that is emerging, especially in the case of program P7, as a way of including ethnocultural groups in environmental programs, it can also be argued that direct targeting will create segmentation within the environmental movement and that as a result of deliberate targeting environmental programming instead of being integrative will become segmented.

For example, in cases where the environmental program was no longer running, no mention was made of what happened to the ethno-cultural groups that had participated. Whether they joined other environmental activities with the same environmental group or whether they ceased their 
involvement with the environmental movement altogether are questions that were beyond the scope of this study. For example, in the case of programs P6a, P6b and P6c, there was a constant focus on Somali and Spanish participants through the evolution of these programs. However in the case of program $\mathrm{P} 7$, which has completed programming for the Chinese community and is now focusing on the South Asian and West Indian communities, it is unclear what will happen to the Chinese participants who attended the energy conservation workshops. Whether they will be contacted for the next round of programming and whether the next round of programming will be funded in a way that will allow for deliberate targeting of specific ethno-cultural groups, are questions that cannot be answered presently.

This issue of inclusion or segmentation also relates to the concepts of multiculturalism. In Canada, it is the intent of multiculturalism to welcome all cultural groups and to include and integrate them into Canadian society. However, if perceived wrongly, deliberate targeting can be viewed as doing the direct opposite - that instead of integrating, it is segmenting and exposing ethno-cultural groups that are not actively participating in the environmental movement.

I would argue that while deliberate targeting is an ideal and logical method for encouraging specific ethno-cultural groups to become initially involved in an environmental program, the program itself should be oriented in a way that will allow its participants to move to other programs within Toronto's environmental movement regardless of whether their ethno-cultural group is deliberately targeted or not.

\section{Traces that Networks Exist}

One way of ensuring environmental programming is oriented in a manner that allows for ethnocultural groups to move to other programs within Toronto's environmental movement is through the use of networks. In the previous chapter the importance of local contacts and interactions were detailed. It was also highlighted that at every key informant mentioned the name of at least one other key informant included in this study or the name of at least one other environmental group included in this study. This suggests that Toronto's environmental groups are in contact 
with each other. Although the nature of their interactions have not been explored in this study, it would be interesting to examine these interactions in more detail and to map out the networks that exists between Toronto's environmental groups and the other groups they interact with.

\section{Discussion and Summary of Key Points}

This chapter presented a critical review of the findings discussed in the previous chapter. It was suggested that the definition of stewardship be expanded and altered to include positive environmental actions that are occurring at the household level and actions which are occurring around non-tangible resources such as air and energy. The ways in which environmental groups encourage ethno-cultural groups to participate in environmental activities was classified into two types, passive and active. Passive interactions are those in which only one-way learning occurs such as when a potential program participant views an environmental group's website. Active interactions are those that facilitate two-way information exchange and learning. Face to face meetings are an example of active interactions.

The ways in which ethno-cultural groups became involved in environmental programs was also classified into two types - deliberate targeting and deliberate siting. Deliberate targeting refers to specifically recruiting predetermined ethno-cultural groups whereas deliberate siting refers to locating an environmental program in an area in which ethno-cultural groups reside. Because the program is located in a diverse area, it would follow that the composition of the program participants would be reflective of the area's population. Deliberate targeting and deliberate siting are not mutually exclusive and can be used together to increase the participation of ethnocultural groups in environmental activities.

While the environmental groups examined displayed ethno-cultural sensitivity through doing background research about ethno-cultural groups, environmental discourse in terms of how programs are presented does not start from the perspective of the targeted ethno-cultural group. This means that ethno-cultural sensitivity is being used to set the framework of the environmental program but it is not being used as a starting point of interaction between the 
environmental and ethno-cultural groups. The deliberate targeting of specific ethno-cultural groups also raised questions about whether this form of encouragement would lead to inclusion or segmentation within Toronto's environmental movement.

As part of Chapter 6: Conclusions, the best practices that can be used by environmental groups to encourage ethno-cultural groups to participate in environmental programs are detailed based on the findings of this study. The following chapter will also recommend future areas of research that would help inform some of the data gaps uncovered in this study. An overall summary of the research is also presented. 


\section{.}




\section{Chapter VI: Conclusions}

The purpose of this chapter is to provide an overview of the study. This chapter will also outline the best practices of how environmental organisations can encourage ethno-cultural groups to participate in environmental programs and suggest areas of future research.

\section{Summary of the Study}

This study examined how environmental groups in Toronto are encouraging ethno-cultural groups to participate in environmental activities. The scope of this study is bound by three areas of research: the environmental movement, volunteering and ethno-cultural diversity. To inform the research question a literature review was undertaken which examined literature from these three fields. This study was undertaken as a pilot study with the intent of gathering exploratory information because this type of study has previously not been undertaken in Toronto.

A literature review was undertaken for this study prior to data collection and analysis which reflects the overlaps of the three areas of study this research intersects. This literature review, presented in Chapter 1: Background and Chapter 2: Enlargement represents the first time these three areas of study have been combined and triangulated to inform a research question specific to Toronto's environmental movement.

Studies such as those by Nivette and Kanji (2003) and the Ethnic Diversity Survey are pieces of literature that also speak to the merging of the environmental movement with other areas of study such as volunteering, civic participation and social capital. The articles by Pickering (1995) and the TRCA's Human Connections video also serve as prime examples of the involvement ethno-cultural groups can have in the environmental movement.

The existing body of volunteer and environmental literature did not reveal that differences in the interpretation of the terms volunteer and participant should be expected when examining different environmental programs which became evident during interviews with key informants. 
Literature specific to multiculturalism in Canada is abundant with differing viewpoints. Multiculturalism literature includes discussions of integration, assimilation, inclusion and segmentation. These concepts were applied in Chapter 5: Analysis to determine the importance and implications of this study's findings.

The current body of literature does not address up-to-date techniques that can be used to encourage ethno-cultural groups to participate in environmental programs. As such, the List of Techniques proposed in Chapter 6: Conclusions has been produced to serve as a starting point for the development of additional techniques which environmental groups can share and discuss with each other.

This study collected primary and secondary data. Primary data was collected through in-person, semi-structured interviews with key informants from ten different environmental groups in Toronto, representing thirteen environmental programs. Because the interviews were semistructured, further probing or clarification of responses was used when necessary. Key informants were individuals who were most closely associated with the environmental programs selected for examination in this study. The interviews were tape recorded and analysed using open, axial and selective coding. Secondary data was gathered through scholarly journals, books, websites and print material published by the environmental groups included in this study.

The environmental programs examined in this study were run by a variety of environmental groups. Some were national environmental groups operating from Toronto whereas others were solely based in Toronto. These groups also represented a wide range of environmental issues as reflected in the programs. For example, some programs focused on urban agriculture and urban gardening whereas others focused on energy conservation.

Eight major finings were discussed:

- Volunteer and Participant Can Have Different Meanings

- Information Gaps Exist: Ethno-cultural Data Not Collected 
- Information Gaps Exist: Motivations Not Formally Collected

- Local Level Interactions are Important

- Environmental Programs are Multi-faceted

- Environmental Groups Do Not Work in Isolation

- Funding Affects Long-term Program Planning

- Cultural Sensitivity is Important

The concepts of deliberate targeting and deliberate siting were discussed as ways to encourage ethno-cultural groups to participate in environmental activities. Active and passive interactions were also examined in terms of recruitment and program structure. It was also suggested that aside from being ethno-culturally sensitive in the planning of an environmental program, environmental discourse should begin from the perspective of the ethno-cultural group as a way to link Canadian and non-Canadian forms of environmentalism and make Canadian environmental issues relevant to ethno-cultural groups. The concept of deliberate targeting was further discussed, raising questions about whether it creates inclusion or segmentation within Toronto's environmental movement.

\section{List of Techniques}

This section will outline techniques that can be used by environmental groups to encourage ethno-cultural groups to participate in environmental activities. These techniques have been developed based on the key informant interviews and the findings of this study. These are the techniques the key informants used in the programs examined to encourage the participation of ethno-cultural groups. It is hoped that these techniques will be implemented and updated as interactions between ethno-cultural and environmental groups become more commonly planned and studied in Toronto and elsewhere. 
1. Start with research: When specifically targeting an ethno-cultural group, research their history, tradition, rites, rituals and beliefs. This provides a richer understanding of their environmental beliefs and values.

2. Use local contacts and local leaders: By approaching local leaders of community groups, faith groups and schools an environmental group can access local knowledge and resources. Local leaders can also be used to disseminate information about an environmental program because they already have credibility with their constituents.

3. Use ethno-cultural specific print, radio and TV media. Instead of advertising in the major newspapers, a more targeted approach would be to place an ad in the local community newspaper that is distributed in the area where an environmental program is going to be held. The same technique can be applied to using local TV stations and local radio stations that broadcast programs in different languages.

4. Use translators: Translators can be useful especially in planning environmental programs targeted to newcomers to Canada. For example, a translator might be needed during a question and answer session of a workshop or training session.

5. Use music: Ethno-cultural specific music can be used to connect with the audience before and after an environmental program activity.

6. Use local sites for programs: Workshops training and information sessions should be held in locally accessible and familiar areas. For example, if targeting the Chinese community residing in Chinatown, hold the workshop near Chinatown so that local residents can attend the session by walking or by taking transit.

7. Provide ethno-culturally specific snacks: Getting to know what the targeted ethnocultural group eats and does not eat shows respect for their customs and traditions.

8. Partner education with recreation: As part of a workshop or training session, incorporate a fun component during which participants can reflect on what they have learned and celebrate their accomplishments.

9. Use the Internet and email: The internet and email are quick and cost-effective ways to promote environmental programs. However face to face contact with ethno-cultural groups allows for two-way information exchange and instant feedback.

10. Approach the ethno-cultural groups: Ethno-cultural groups may not know how to contact or where to find environmental groups. However, ethno-cultural groups can easily be found and personally contacted by visiting community centres, ESL classes, churches, mosques and ethno-cultural specific festivals or events. 
11. Start environmental dialogue from the perspective of the ethno-cultural group: Ask the group about their ways of traditional environmentalism and relate these concepts to the focus of the environmental program.

\section{Directions for Future Research}

This study was undertaken as an exploratory study to get a general sense of how environmental groups are encouraging ethno-cultural groups to participate in environmental programs in Toronto. The findings of this study indicate that further research is needed in various areas. An area that could be examined further is participant and volunteer motivation. Learning more about why different ethno-cultural groups participate in environmental programs would help shape the direction of future interactions these groups have between environmental groups. To uncover these motivations more accurately, a study from the perspective of the volunteers or participants should be undertaken. The results of such a study could be compared with the results of this study to examine whether the motivations offered by the key informants reflect the actual motivations of participants and volunteers. Disconnects between the two groups could also be uncovered by such a study and this would shape the nature of program planning and implementation to satisfy any new motivations that were uncovered. Further thought will have to be given to how volunteer or participant contact information can be obtained from the environmental groups without contravening confidentiality rules that the environmental group might have in place.

In terms of ethno-cultural specific data collection, while this is not formally collected by environmental groups a project for future development could be the creation of a participant registration form or survey that several environmental groups would use over a period of time. The results of such a survey or registration form could then be compared with the ethno-cultural composition of the areas in which these groups are based or operate, to give a clearer sense of the groups that are being reached and those which could be specifically targeted for inclusion in environmental programs. One approach to this research would be to develop a survey that is similar to the NSGVP which anonymously asks about motivations, barriers and recruitment, which could be administered to participants and volunteers. 
The collection of ethno-cultural data along with participant and volunteer motivations will allow environmental programs to be tailored to various ethno-cultural groups. The collection of this type of data can be viewed as being a precursor to engaging in environmental discourse with ethno-cultural groups from their perspective. I would argue that these three actions: (1) collecting ethno-cultural data; (2) learning about motivations; and (3) beginning environmental discourse from non-Canadian perspectives can be viewed as measures of success in integrating and fully engaging ethno-cultural groups in environmental activities in Toronto.

This study revealed that environmental groups work with other groups to plan and implement environmental programs. Future research that examines these networks more carefully would provide information about the types of organisations environmental groups are partnering with and the resources - tangible and non- tangible - that are leveraged through such partnerships.

The best practices detailed above should also be subjected to further investigation in terms of their application and relevance in different types of environmental programs, aside from the ones examined in this study. A study detailing how often and in what combinations these best practices are used to attract ethno-cultural groups to environmental programs would be beneficial to environmental groups.

This study could also be expanded to other Canadian provinces or to other countries to compare the ways in which other environmental groups are encouraging ethno-cultural participation in environmental activities. It is hoped that this study will serve as a starting point for further investigation into the interactions that occur between environmental and ethno-cultural groups in Toronto and else where. 


\section{Appendix A: Basic Stewardship Types}

\section{Basic Stewardship Activities}

Definitions of basic stewardship types developed by Lerner and Reid (1993):

\section{Advocacy}

Activity, typically partisan and of a political nature, undertaken in support of maintaining the existence and / or well-being of some aspect of natural world (e.g. a specific site or species of flora or fauna) or quality of environmental life support systems.

\section{Conservation}

Activity that involves striving for more efficient management of renewable resources to achieve an optimum sustainable yield from a particular resource (e.g. timber, fisheries), the elimination of waste from harvesting practices and / or the 'balanced use' of resources among different groups.

\section{Education}

Activity undertaken with the aims of: heightening awareness of the natural world; increasing people's understanding of nature in general or some aspect of the natural world; helping develop skills that can be used in the service of the natural world; helping develop concern for and commitment to the well-being of that natural world.

\section{Monitoring}

The regular collection of information about a natural feature or area by observation, measurement or other means - keeping track of environmental conditions (e.g. water quality, health of local fish and wildlife) or human activities associated with environmental degradation.

\section{Preservation}

Activity undertaken to preserve nature to the maximum extent possible from development and / or other human disturbances, especially of the type that involves the physical transformation of the resource in question.

\section{Restaration}

Activity to return a site or its ecological components to some condition considered socially and / or environmentally preferable to an existing condition. 


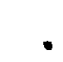

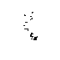




\section{Appendix B: Interview Protocol}

\section{Section A: General Questions}

When did you start your association with this organisation?

What is your current role within this organisation?

What previous roles, if any, have you had with this organisation?

What are the main activities of your organisation?

Since when has your organisation has been operating in these activities?

\section{Section B: Project Specific Questions}

When did program $\mathrm{X}$ begin?

Is the program still operating? [] No [] Yes

How often did volunteers for the program X meet for stewardship projects?

How many volunteers would you estimate were involved in program X?

What were the proportions different ethno-cultural groups that volunteered for program $\mathrm{X}$ ?

Ethno-cultural Group

Proportion of total project volunteers

What proportion of the volunteers for this program would you say had been in Canada for 5 years or less?

Of those mentioned in Question, 11 who had probably been in Canada for 5 years or less, which ethno-cultural groups were they from?

\section{Section C: Project Specific Questions}

Do you know the reason for establishing program $\mathrm{X}$ ?

Can you describe the types of stewardship activities that volunteers would undertake for program $\mathrm{X}$ ? 


\section{Motivation for Involving Ethno-cultural Volunteers}

Can you tell me how volunteers from different ethno-cultural groups became involved in program X?

Anecdotally, from your experience as co-ordinator for program $\mathrm{X}$ can you offer reasons why volunteers from different ethno-cultural groups became involved in the project?

\section{Networks / Partnerships}

For program X did your organisation work with any other organisations

(a) For volunteer recruitment and volunteer training?

(b) For material support such as funding, work/field/project space, other in-kind support?

(c) Program planning and implementation?

(d) Other?

During what facets of the project was the relationship between your organisation and the organisations mentioned above active? (planning, recruitment, funding, implementation on the day of the event or training the volunteers)

Can you tell me how program $\mathrm{X}$ was funded? (funding partners, grant giving organisations)

\section{Lessons Learned}

Did you change any of the normal practices your organisation uses to carry out volunteer stewardship activities for program $\mathrm{X}$ because different ethno-cultural groups were involved?

(a) for volunteer recruitment and volunteer training

(b) for material support such as funding, work/field/project space, other in-kind support

(c) program planning and implementation

(d) other aspects

Do you know the reasons these aspects where changed?

Can you describe aspects of program $\mathrm{X}$ that remained unchanged?

Do you know the reasons these aspects remained unchanged? 


\section{Appendix C: Isolating the Selected Environmental Programs}

Isolating the selected environmental groups and programs involved a lengthy process. These programs were difficult to isolate because most existing environmental directories do not classify environmental groups based on interactions with ethno-cultural groups.

Sustainability Network's 2001 Ontario Directory: Ethno-Cultural Organizations and the Environment was a resource that attempted to highlight environmental groups which have interacted with ethno-cultural groups. Finding this directory was accidental. I had never heard of it before nor had any of my potential key informants mentioned it to me during my initial introduction to them about my research. I came across this directory doing a Google Internet search using various combinations of key words related to this study such as ethno-cultural groups, environmental groups, environmental organisations, volunteering and Toronto. Once I downloaded this directory, I began a search to find a hard copy of it. I searched the library databases of Ryerson University, the University of Toronto, York University and the database of the Toronto Public Library System to no avail. It appears that the Internet posting of this directory on Sustainability Network's website is the only place this directory is accessible.

I also contacted Sustainability Network because I wanted to speak to Ms. Mitra, the author of the study. I was informed that Ms. Mitra was no longer with Sustainability Network.

The TRCA's environmental fair for newcomers was another way in which these groups were isolated. However, the environmental groups showcased at this fair were quite diverse and I could not assume that because the environmental groups participated in this fair that they were encouraging ethno-cultural groups to participate in environmental activities. I therefore had to speak to each group representative individually to gain a basic understanding about the group's main activities and interest in the environmental movement. 


\section{.}




\section{Works Cited}

“About Us.” Evergreen. 2004. Evergreen Canada. 23 May 2005.

$<$ http://www.evergreen.ca/en/about/about.html $>$.

Advisory Board on the Voluntary Sector. Voluntary Action: Sustaining a Civic Society in Ontario - The Report of the Advisory Board on the Voluntary Sector. Toronto: The Advisory Board on the Voluntary Sector, 1997.

Agyeman, Julian. "Culturing Environmental Education: From First Nation to Frustration." Canadian Journal of Environmental Education 7.1 (2002): 2-12.

Aizlewood, Amanda and Ravi Pendakur. Ethnicity and Social Capital in Canada. Ottawa: Department of Canadian Heritage, 2004.

Badets, Jane. Canadian Social Trends: Update on Cultural Diversity. Ottawa: Statistics Canada, 2003.

Baker, Lauren. Seeds of Our City. Toronto: Food Share, 2002.

Bechtel, R. B., V. C. Verdugo and J. Pinheiro. "Environmental Belief Systems: United States, Brazil and Mexico." Journal of Cross Cultural Psychology 30.1 (1998): 122-28.

Bissoondath, Neil. Selling Illusions: The Cult of Multiculturalism in Canada. Toronto: Penguin Books, 1994.

Blee, Kathleen M. and Verta Taylor. "Semi-structured Interviewing in Social Movement Research." Klandermans and Staggenborg 92-117.

Bozzo, Sandra. Motivations for Giving and Volunteering: Fact Sheet \#6. Toronto: Canadian Centre for Philanthropy, 1999.

Brechin, S. R. and W. Kempton, "Global Environmentalism: A Challenge to the Postmaterialist Thesis?" Social Science Quarterly 75.2 (1994): 245-69.

Bullard, Robert D. 2000 Directory People of Colour: Environmental Groups. Georgia:

Environmental Resource Centre: Clark Atlanta University, 2000.

---. Dumping in Dixie: Race, Class, and Environmental Quality. Boulder: Westview Press, 1990.

---. Unequal Protection: Environmental Justice and Communities of Color. San Francisco: Sierra Club Books, 1994. 
Bunyan, Bryant and Paul Mohai. Race and the Incidence of Environmental Hazards: The Time for Discourse. Boulder: Westview Press: 1990.

Camacho, David, ed. Environmental Injustices, Political Struggles: Race, Class and the Environment. Durham: Duke University Press, 1998.

Canada. Department of Canadian Heritage and Statistics Canada. Ethnic Diversity Survey. Ottawa: Statistics Canada, 2003.

Canadian Centre for Philanthropy. Giving and Volunteering of New Canadians. Toronto: Canadian Centre for Philanthropy, 2004a.

--- Motivations and Barriers to Volunteering. Toronto: Canadian Centre for Philanthropy, 2004b.

---. The Giving and Volunteering of New Canadians. Toronto: Canadian Centre for Philanthropy, 2004c.

---. Volunteering in Ontario. Toronto: Canadian Centre for Philanthropy, 2003.

"Canadian Diversity: Respecting Our Differences." Canadian Heritage: Multiculturalism. 2004. Government of Canada. 23 May 2005.

$<$ http://www.pch.gc.ca/progs/multi/respect_e.cfm>.

"Canadian Multiculturalism: An Inclusive Citizenship." Canadian Heritage: Multiculturalism. 2004. Government of Canada. 23 May 2005.

$<$ http://www.pch.gc.ca/progs/multi/inclusive_e.cfm>.

Clary, Gil E. and Mark Snyder. "The Motivations to Volunteer: Theoretical and Practical Considerations." Current Directions in Psychological Science 8.5 (1999): 156-9.

"Corporate Information." Toronto and Region Conservation for the Living City. n.d. Toronto and Region Conservation Authority. 23 May 2005. <http://www.trca.on.ca/corporate_info/>.

"Community Development for Multicultural Environmental Stewardship Program." Toronto and Region Conservation for the Living City. n.d. Toronto and Region Conservation Authority. 11 Aug. 2003.

$<$ http://www.trca.on.ca/event/stewardship_programs/default.asp\#multicultural>.

Diani, Mario. "Network Analysis." Klandermans and Staggenborg 173-200.

Diana Mario and Giovanni Lodi. "Three in One: Currents in the Milan Ecology Movement." Klandermans, Kriesi and Tarrow 103-124. 
Donald, Betsy J. "Fostering Environmetnal Volunteerism in an Environmental Stewardship Group: Report on the Task Force to Bring Back the Don, Toronto, Canada." Journal of Environmental Planning and Management 40.4 (1997): 483-505.

Dryzek, John S. and David Schlosberg, eds. Debating the Earth: The Environmental Politics Reader $2^{\text {nd }}$ ed. New York: Oxford University Press, 2004

Dunlap, Riley E., George H. Gallup and Alec M. Gallup. "Of Global Concern: Results of the Health of the Planet Survey." Environment 35.9 (1993a): 7-33.

---. "A Global Environmental Concern: Results from an International Public Opinion Survey." Environment 35.9 (1993b): 7-39.

Durning, Alan B. "Mobilizing at the Grassroots." Ed. Lester R. Brown. State of the World. New York: Norton Press, 1989. 154-73.

"Ecoaction Teams: Program Summary." Earth Day Canada: Year Round Programs. 2003. Earth Day Canada. 23 May 2005.

$<$ http://www.earthday.ca/EDy2k/YearRnd/YearRndfrm1.html>.

Ewert, Alan W., Deborah J. Chavez and Arthur W. Magill, eds. Culture Conflict and Communication in the Wildand-urban Interface. Boulder: Westview Press, 1993.

Feagan, Robert B. "Expanding Worldviews: Social Movement Backgrounds Bring a Deeper Analysis to the Environmental Movement." Alternatives. 20.2 (1994): 26-31.

Fischer, Claude S. Networks and Places: Social Relations in the Urban Setting. New York: Free Press, 1977.

Flood, Robert L. and Ewart R. Carson. Dealing With Complexity - An Introduction to the Theory and Application of Systems Science. $2^{\text {nd }}$ ed. New York: Plenum, 1993.

Floyd, M. F. and F. P. Noe. "The New Environmental Paradigm and Hispanic Cultural Influence." Eds. Alan W. Ewert, Deborah J. Chavez and Arthur W. Magill. Culture Conflict and Communication in the Wildand-urban Interface. Boulder: Westview Press, 1993. 85-98.

Galson, William A. Liberal Purposes: Goods, Virtues, and Diversity in the Liberal State. New York: Cambridge University Press, 1991.

Gobster, Paul H. and R. Bruce Hull, eds. Restoring Nature: Perspectives from the Social Sciences and Humanities. Washington: Island Press, 2000.

Gosine, Andil. "Myths of Diversity." Alternatives. 29.1 (2003): 12-17. 
Gray, George A. and Neil Guppy. Successful Surveys: Research Methods and Practise. $2^{\text {nd }}$ ed. Toronto: Harcourt Brace, 1999.

Greenberg, Liane and Sandra Bozzo. Giving and Volunteering in Ontario: Results from the National Survey of Giving Volunteering and Participating. Toronto: Canadian Centre for Philanthropy, 2001.

Gwyn, Richard J. Nationalism without Walls: The Unbearable Lightness of Being Canadian. Toronto: McClelland and Stewart, 1995.

Hannabuss, Stuart. "Research Interviews." New Library World. 97.1129 (1996): 22-30.

Harper, Douglas. "Ethno." Online Etymology Dictionary. 2001. Online Etymology Dictionary. 23 May 2005. $<$ http://www.etymonline.com/index.php?search=ethno\&searchmode=none $>$.

"History of Volunteerism." Community Resource Network of Greater Sudbury. 2004. Social Planning Council of Sudbury. 31 Jan. 2005. $<$ https://www.crnet.ca/English/volunteer/why_volunteer/why_volunteer.html $>$.

Hokenmaier, Sarah Conolly. "Civic Environmentalism. Learning to Give - An Action of the Heart, a Project for the Mind." Learning to Give: An Action of the Heart, Project of the Mind. 2005. Center on Philanthropy at Indiana University. 24 Jun. 2005. $<$ http://www.learningtogive.org/papers/index.asp?bpid $=10>$.

Human Connections: Multiculturalism and the Environment. Prod. Eyes Post Group. Toronto and Region Conservation Authority, 2000.

Johnson, Cassandra Y., J. M. Bowker and H. Ken Cordell. "Ethnic Variation in Environmental Belief and Behaviour - An examination of New Ecological Paradigm in a Social Psychological Context." Environment and Behavior 36.2 (2004): 157-86.

Johnston, Richard and Stuart Soroka. "Social Capital in a Multicultural Society: The Case of Canada." 1999. University of British Columbia. 31 Jan. 2005. $<$ http://www2.arts.ubc.ca/cresp/rjmulti.pdf $>$.

Kalland, Arne and Gerard Persoon, eds. An Anthropological Perspective on Environmental Movements in Asia. London: Curzon, 1998.

Karau, S. J. and K. D. Williams. "Social Loafing: A Meta-analytic Review and Theoretical Integration." Journal of Personality and Social Psychology 65 (1993): 681-706.

Kato, Kumi. "Environment and Culture: Developing Alternative Perspectives in Environmental Discourse." Canadian Journal of Environmental Education 7.1 (2002): 110-116. 
Klandermans, Bert, Hanspeter Kriesi and Sidney Tarrow, eds. From Structure to Action: Comparing Social Movement Research Across Cultures. Greenwich: JAI Press, 1988.

Klandermans, Bert and Suzanne Staggenborg, eds. Methods of Social Movement Research. Minneapolis: University of Minnesota Press, 2002.

Kymlicka, Will. Finding Our Way: Rethinking Ethno-cultural Relations in Canada. Toronto: Oxford Press, 1998.

Kymlicka, Will and Wayne Norman, eds. Citizenship in Diverse Societies. New York: Oxford University Press, 2000.

Lasby, David. The Volunteer Spirit in Canada: Motivations and Barriers. Toronto: Canadian Centre for Philanthropy, 2004.

Lasby, David and David McIver. Where Canadians Volunteer: Volunteerism by Type of Organization. Toronto: Canadian Centre for Philanthropy, 2004.

Lerner, Sally. "Environmental Constituency-Building: Local Initiatives and Volunteer Stewardship." Alternatives 13.3 (1986): 55-60.

---, ed. Environmental Stewardship - Studies in Active Earth Keeping. Waterloo: Department of Geography, University of Waterloo, 1993.

---. "Local Stewardship - Training Ground for an Environmental Vanguard." Alternatives 20.2 (1994): 105-131.

Lerner, Sally and Susanna Reid. "A Study of Ontario Volunteer Environmental Stewardship; Groups." Ed. Sally Lerner. Environmental Stewardship - Studies in Active Earth Keeping. Waterloo: Department of Geography, University of Waterloo, 1993.

Lichtermann, Paul. "Piecing Together Multicultural Community: Cultural Differences in Community Building Among Grass Roots Environmentalists." Social Problems 42.4 (1995): 513-24.

MacIntosh, Robert. The Green List: A Guide to Canadian Environmental Organizations and Agencies. Ottawa: Canadian Environmental Network, 2002.

Magocsi, Paul Robert, ed. Encyclopedia of Canada's People. Toronto: University of Toronto Press, 1999.

McDowell, Linda and Joanne P. Sharp, eds. A Feminist Glossary of Human Geography. New York: Arnold, 1999. 
McKeown, Larry, Giving and Volunteering of New Canadians: Factsheet \#12. Toronto:

Canadian Centre for Philanthropy, 2000.

Miles, I., W. C. Sullivan and F. E. Kuo. "Ecological Restoration Volunteers: The Benefits of Participation." Ecological Restoration 2.1 (1998): 27-41.

Mitra, Ranjana. 2001 Ontario Directory: Ethno-Cultural Organizations and the Environment. Toronto, Sustainability Network, 2001.

Neuman, William Lawrence. Social Research Methods: Qualitative and Quantitative Approaches. Boston: Allyn and Bacon, 2000.

Nivette, Neil and Mebs Kanji. Immigrant Orientation Towards Sustainability: Evidence from the Canadian World Values Surveys. Toronto: Citizenship and Immigration Canada, 2003.

Ontario. Ministry of Finance. Census 2001 Highlights: Factsheet 6 - Visible Minorities in Ontario. Ontario: Queen's Printer for Ontario, 2003.

Padro, M. "Mexican American Women Grassroots Community Activists: Mothers of East Las Angeles." Frontiers: A Journal of Women Studies 11.1 (1990): 1-7.

Parker, J. D. and M. H. McDonough. "Environmentalism of African Americans: An Analysis of the Subculture and Barriers Theories." Environment and Behavior 31 (1999): 155-77.

Pfeffer, Max and J. Mayone Stycos. "Immigrant Environmental Behaviors in New York City." Social Science Quarterly 83.1 (2002): 64-81.

Pickering, Mary. "New Canadians Enrich Environmental Activism." Alternatives 21.4 (1995): 13-14.

Ponting, Clive. A Green History of the World: The Environment and the Collapse of Great Civilizations. New York: Penguin, 1991.

Putnam, Robert. Bowling Alone: The Collapse and Revival of American Community. New York: Simon and Schuster, 2000.

Rondinelli, Dennis A. and Ted London. Partnering for Sustainability: Managing Nonprofit Organization-Corporate Environmental Alliances. Washington: Aspen Institute, 2001.

Russel, Dick. "Environmental Racism: Minority Communities and their Battle Against Toxics." Amicus Journal 11 (1989): 22-23. 
Ryan, Robert L., Rachel Kaplan and Robert E. Grese. "Predicting Volunteer Commitment in Environmental Stewardship Programs." Journal of Environmental Planning and Management 44.5 (2001): 629-48.

Schawb, James. Deeper Shades of Green: The Rise of Blue-Collar and Minority Environmentalism in America. San Francisco: Sierra Club Books, 1994.

Schlosberg, David. "Networks and Mobile Arrangements: Organizational Innovation in the US Environmental Justice Movement." Dryzek and Schlosberg 122-48.

Schrecker, Ted. "Environmentalism and the Politics of Invisibility." Alternatives 20.2 (1994): 32-7.

Schroeder, Herbert W. "The Restoration Experience: Volunteers' Motives, Values and Concepts of Nature. Gobster and Hull 247-64.

Schugurensky, Daniel. "Civic Participation - On Active Citizenship, Social Capital and Public Policy." Canadian Diversity 2.1 (2003): 10-12.

Schultz, P. Wesley. "Environmental Attitudes and Behaviors Across Cultures." Online Readings in Psychology and Culture: Unit 8 Chapter 4. 2002. Western Washington University. $<$ http://www.ac.wwu.edu/ culture/Schultz.htm>.

---. "Empathizing with Nature: The Effects of Perspective Taking on Concern for Environmental Issues." Journal of Social Issues 56 (2000): 391-406.

Schultz, P. Wesley, J. B. Unipan and R. J. Gamba. "Acculturation and Ecological Worldview Among Latin Americans." The Journal of Environmental Education 31.2 (2000): 22-7.

Sirianni, Carmen and Lewis Friedland. "Social Capital." Tools: Civic Dictionary. n.d. Civic Practices Network. 31 Jan 2005. <http://www.cpn.org/tools/dictionary/capital.html>.

Taylor, Dorceta E. "American Environmentalism: The Roles of Race, Class, and Gender in Shaping Activism, 1820-1995." Race, Class and Gender 5 (2000): 16-62.

---. "Can the Environmental Movement Attract and Maintain Support of Minorities?" Bunyan and Mohai 28-40.

---. "Environmentalism and the Politics of Inclusion." Ed. Robert Bullard. Confronting Environmental Racism: Voices from the Grassroots. Boston, South End Press, 1993. 5362.

"The Work of Future Watch." About Us. n.d. Future Watch Environment and Development Education Partners. 23 May 2005. <http://www.futurewatch.net/aboutus.html>. 
Toronto. City of Toronto Task Force on Community Access and Equity. Glossary of Equity and Access Terms. Toronto: City of Toronto, 1999.

"Toronto Environmental Volunteers." Get Involved. 2005. City of Toronto. 28 Jan 2005. $<\mathrm{http}: / / \mathrm{www} . c i t y . t o r o n t o . o n . c a /$ wes/techservices/involved/outreach/tev/>.

"Toronto's Racial Diversity." Living in Toronto. 2005. City of Toronto. 28 Jan. 2005. $<\mathrm{http} / /$ www.bedfordstmartins.com/online/cite5.html\#1>.

Tossutti, Livianna. "A Tradition of Social Science Capital In Minority Communities." Canadian Diversity 2.1 (2003): 17-19.

Tocqueville, A. de. Democracy in America. Trans. Henry Reeve. New York: Schocken Books, 1961.

Verdugo, V. Corral. and L. I. Armendáriz. "The New Environmental Paradigm in a Mexican Community." The Journal of Environmental Education 31.3 (2000): 25-31.

"Visible Minority Population by Provinces and Territories." Canadian Statistics. 2005. Statistics Canada. 15 Jul. 2005. <http://www40.statcan.ca/101/cst01/demo52a.htm>.

Voyer, Jean-Pierre, "Diversity without Divisiveness: A Role for Social Capital." Canadian Diversity 2.1 (2003): 31-32.

Waldron, Jeremy. "Cultural Identity and Civic Responsibility." Kymlicka and Norman 155-74.

Wall, Gelda. "Barriers to Individual Environmental Action: The Influence of Attitudes and Social Experience." The Canadian Review of Sociology and Anthropology 32.4 (1995): 465-91.

"Welcome to the Stewardship Website." Living in Toronto. 2005. City of Toronto. 23 May 2005. $<$ http://www.toronto.ca/greentoronto/s.

Wellman, Barry, Peter Carrington and Alan Hall. Networks as Personal Communities. Toronto: Centre for Urban and Community Studies, 1983.

Wellman, Barry and Steven D. Berkowitz, eds. Social Structures: A Network Approach. New York: Cambridge University Press, 1988.

Westphal, Lynne M. "Birds Do It, Bees Do It, But Why do Volunteers Do It? A Look at Motivation." 1993 Proceedings of the Midwest Oak Savanna Conferences. 2003. U.S. Environmental Protection Agency. 5 Aug 2004.

<http://www.epa.gov/glnpo/ecopage/upland/oak/oak93/westphal.html>. 
"Who We Are." The Conservation Council of Ontario 2002. The Conservation Council of Ontario. 23 May 2005. <http://www.greenontario.org/cco/who.html>.

Yearly, Steven. Sociology, Environmentalism, Globalization: Reinventing the Globe. Thousand Oak: Sage, 1996.

Yechen, David, "Attitudes to Nature in the East and West." Eds. David Yechen, John Fien and Helen Skyes. Environment Education and Society in the Asia-Pacific. London:

Routledge, 2000. 4-27. 
$9 x \cdot 74: 54$ 